\title{
Article \\ Nanocurcumin-Loaded UCNPs for Cancer Theranostics: Physicochemical Properties, In Vitro Toxicity, and In Vivo Imaging Studies
}

\author{
Anbharasi Lakshmanan ${ }^{1}$, Roman A. Akasov 2,3,4,*(D), Natalya V. Sholina 2,3, Polina A. Demina 4 (D), \\ Alla N. Generalova ${ }^{3,4} \mathbb{D}^{D}$, Ajithkumar Gangadharan ${ }^{5,6}$, Dhiraj K. Sardar ${ }^{5,6}{ }^{(\mathbb{D}}$, Krishna Bharat Lankamsetty ${ }^{7}(\mathbb{D}$, \\ Dmitry A. Khochenkov ${ }^{8,9} \mathbb{D}^{\mathbb{D}}$, Evgeny V. Khaydukov 2,3 ${ }^{\mathbb{D}}$, Sergey V. Gudkov 10,11(D), Manonmani Jayaraman ${ }^{12}$ \\ and Senthilselvan Jayaraman $1, *$
}

Citation: Lakshmanan, A.; Akasov, R.A.; Sholina, N.V.; Demina, P.A.; Generalova, A.N.; Gangadharan, A.; Sardar, D.K.; Lankamsetty, K.B.;

Khochenkov, D.A.; Khaydukov, E.V.; et al. Nanocurcumin-Loaded UCNPs for Cancer Theranostics:

Physicochemical Properties, In Vitro Toxicity, and In Vivo Imaging Studies. Nanomaterials 2021, 11, 2234. https:// doi.org/10.3390/nano11092234

Academic Editor: Pablo Botella

Received: 23 July 2021

Accepted: 16 August 2021

Published: 29 August 2021

Publisher's Note: MDPI stays neutral with regard to jurisdictional claims in published maps and institutional affiliations.

Copyright: (c) 2021 by the authors. Licensee MDPI, Basel, Switzerland. This article is an open access article distributed under the terms and conditions of the Creative Commons Attribution (CC BY) license (https:// creativecommons.org/licenses/by/ $4.0 /)$.
1 Department of Nuclear Physics, Guindy Campus, University of Madras, Chennai 600025, Tamil Nadu, India; anbhulaksh118@gmail.com

2 I M Sechenov First Moscow State Medical University, 119991 Moscow, Russia; sholinanv@gmail.com (N.V.S.); khaydukov@mail.ru (E.V.K.)

3 Federal Scientific Research Center, "Crystallography and Photonics", Russian Academy of Sciences, Leninskiy Prospekt 59, 119333 Moscow, Russia; angeneralova@gmail.com

4 Shemyakin-Ovchinnikov Institute of Bioorganic Chemistry, RAS, 117997 Moscow, Russia; polidemina1207@yandex.ru

5 Department of Physics and Astronomy, University of Texas at San Antonio, San Antonio, TX 78249, USA; akgsh2005@gmail.com (A.G.); Dhiraj.Sardar@utsa.edu (D.K.S.)

6 Department of Natural Sciences, Texas Agriculture and Mechanical University, One University Way, San Antonio, TX 78224, USA

7 Federal State Budgetary Scientific Institution "Federal Scientific Agroengineering Center VIM" (FSAC VIM), 109428 Moscow, Russia; krish.agudguy@gmail.com

8 FSBI "N.N. Blokhin National Medical Research Center for Oncology", Ministry of Health of the Russian Federation, Kashirskoe Shosse 24, 115478 Moscow, Russia; khochenkov@gmail.com

9 Medicinal Chemistry Center, Togliatti State University, Belorusskaya Str. 14, 445020 Togliatti, Russia

10 Biophotonics Center, Prokhorov General Physics Institute of the Russian Academy of Sciences, Vavilova St. 38, 119991 Moscow, Russia; s_makariy@rambler.ru

11 Department of Closed Artificial Agroecosystems for Crop Production, Federal State Budgetary Scientific Institution "Federal Scientific Agroengineering Center VIM" (FSAC VIM), 5 First Institutskiy pr-d, 109428 Moscow, Russia

12 Department of Chemistry, Quaid-E-Millath Government College for Women, Chennai 600002, Tamil Nadu, India; jmanon32@gmail.com

* Correspondence: roman.akasov@gmail.com (R.A.A.); jsselvan@hotmail.com or jsselvan16@gmail.com (S.J.)

Abstract: Formulation of promising anticancer herbal drug curcumin as a nanoscale-sized curcumin (nanocurcumin) improved its delivery to cells and organisms both in vitro and in vivo. We report on coupling nanocurcumin with upconversion nanoparticles (UCNPs) using Poly (lactic-co-glycolic Acid) (PLGA) to endow visualisation in the near-infrared transparency window. Nanocurcumin was prepared by solvent-antisolvent method. $\mathrm{NaYF}_{4}: \mathrm{Yb}, \mathrm{Er}(\mathrm{UCNP} 1)$ and $\mathrm{NaYF}_{4}: \mathrm{Yb}, \mathrm{Tm}(\mathrm{UCNP} 2)$ nanoparticles were synthesised by reverse microemulsion method and then functionalized it with PLGA to form UCNP-PLGA nanocarrier followed up by loading with the solvent-antisolvent process synthesized herbal nanocurcumin. The UCNP samples were extensively characterised with XRD, Raman, FTIR, DSC, TGA, UV-VIS-NIR spectrophotometer, Upconversion spectrofluorometer, HRSEM, EDAX and Zeta Potential analyses. UCNP1-PLGA-nanocurcumin exhibited emission at 520, 540, $660 \mathrm{~nm}$ and UCNP2-PLGA-nanocurmin showed emission at 480 and $800 \mathrm{~nm}$ spectral bands. UCNPPLGA-nanocurcumin incubated with rat glioblastoma cells demonstrated moderate cytotoxicity, $60-80 \%$ cell viability at $0.12-0.02 \mathrm{mg} / \mathrm{mL}$ marginally suitable for therapeutic applications. The cytotoxicity of UCNPs evaluated in tumour spheroids models confirmed UCNP-PLGA-nanocurcumin therapeutic potential. As-synthesised curcumin-loaded nanocomplexes were administered in tumourbearing laboratory animals (Lewis lung cancer model) and showed adequate contrast to enable in vivo and ex vivo study of UCNP-PLGA-nanocurcumin bio distribution in organs, with dominant 
distribution in the liver and lungs. Our studies demonstrate promise of nanocurcumin-loaded upconversion nanoparticles for theranostics applications.

Keywords: upconversion nanoparticles; theranostics; nanocurcumin; herbal drugs; intravital imaging

\section{Introduction}

Cancer is a major global health issue that needs novel approaches in addition to conventional surgical resection, chemotherapy, or radiotherapy [1]. Over the past decade, by the advancement in BioNanoMedicine, nanoparticles with various natures have attracted more attention as cancer theranostics agents that combine both visualization and therapy modalities. Drug carriers based on nanoparticles have lower side effects compared to the free drug, demonstrate increased tumour-specific targeting as a result of the enhanced permeability and retention (EPR) effect, and can provide controlled drug release, which makes the use of nanodrug delivery systems a promising approach in bionanomedicine [2].

Rare earth-doped upconversion nanoparticles (UCNPs) are a unique category of optical nanomaterials that exhibit anti-Stokes process of converting the near infrared radiation (NIR) to visible/NIR emission [3]. UCNPs demonstrate unique optical properties, including high penetration into biological tissues due to so called near-infrared transparency window, high resistance to photobleaching, absence of autofluorescence, multicolour emission with a narrow line width, high luminescence lifetime, low irradiation damage, and increased signal-to-noise ratio and photochemical stability [4]. These properties make UCNPs an excellent platform for biovisualization. However, UCNPs could additionally be loaded with antitumor drugs to obtain a theranostics platform with both visualization and therapeutic properties [5].

Curcumin is a yellow coloured polyphenol compound that has many promising biomedical properties like anti-oxidant [6], anti-fungal effect [7], anti-inflammatory, antiproliferative [8], antiviral [9] effects, etc. It has been reported that therapeutic efficacy of curcumin is useful in the treatment of digestive and reproductive system cancers, haematological and brain tumours, urological cancer, breast cancer, and bone tumours [10]. The main problem of curcumin is hydrophobicity, which leads to poor water solubility, low absorption, quick drug metabolism, low penetration, and degradation $[1,7,11-13]$. The oral bioavailability of curcumin is limited, as it gets unabsorbed due to little intestinal absorption capability. Even the slightly absorbed part rapidly metabolized. Therefore, rapid metabolism and excretion causes certain difficulties in using curcumin for biomedical and clinical applications [11,14-19]. To solve the aforesaid problems, encapsulation of the curcumin to nanoformulations is of great interest. The efficacy of curcumin nanoformulations has been demonstrated earlier. Rupesh Kumar Basniwal et al. evaluated the anticancer properties of nanocurcumin in the presence of cancer cell lines such as lung (A549), liver (HepG2) and skin (A431) cancer cells and nanocurcumin exhibited increased anticancer properties over the conventional curcumin formulations [20]. Here, we propose nanocurcumin as model antitumor drug for loading into the nanocomplexes based on UCNPs for theranostics applications.

Although various synthesis methods were reported to prepare $\mathrm{NaYF}_{4} \mathrm{UCNPs}$, pharmaceutically important microemulsion synthesis strategy is important for drug delivery applications and therefore this synthesis methodology was adopted in the present work. It is able to provide sustained drug release, improved drug solubility and enhanced drug absorption. Specifically, the reverse microemulsion (water-in-oil, hydrophilic-lipophilic balance $<10$ ) is an effective method to prepare hexagonal $\mathrm{NaYF}_{4}: \mathrm{Yb}, \mathrm{Er} / \mathrm{Tm} \mathrm{UCNPs}$ [21-23]. Poly (lactic-co-glycolic acid) (PLGA), which is known for attractive biocompatibility, nontoxic nature and high stability, has been proposed to enhance the surface properties of UCNPs within nanocurcumin loading. Drug delivery of curcumin accompanied by PLGA could increase therapeutic efficacies to promote sustained drug delivery and drug release 
targeting, minimize the non-specific consumption by undesirable tissues and to enhance the aqueous solubility $[10,24,25]$. Adeeb Shehzad and co-workers reported so as curcumin incorporated PLGA nanoparticles have exhibited increased cellular uptake, induced the apoptosis and suppressed tumour cell proliferation and improved the bioavailability [10].

The advantage of combining UCNP and nanocurcumin is that the upconverted visible light could excite the photosensitizer and favour fluorescence resonance energy transfer (FRET). The UCNPs could also applicable for photodynamic therapy and photothermal therapy of cancers. NIR excitation based cancer therapy using UCNP that lies in the biological windows is advantageous than quantum dots and other fluorophores. The NIR activation of UCNPs could accomplish photothermal conversion and provide deep tissue penetration ability $[3,26]$. The rare-earth doped $\mathrm{NaYF}_{4}$ is attractive in biomedical applications as it gives high upconversion quantum yield than the quantum dots by two-photon energy transfer process from the sensitizer ion and the activator ion.

We report on synthesis and characterisation of biofunctional nanocomplexes of $\mathrm{NaYF}_{4}$ : $\mathrm{Yb}$,Er and $\mathrm{NaYF}_{4}: \mathrm{Yb}$,Tm upconversion nanoparticles surface-coated with PLGA and nanocurcumin. The phase formation, morphology and basic upconversion emission properties of the synthesised UCNP complexes were investigated. Besides, in vitro cytotoxicity of the biofunctional nanocomplexes was tested using rat glioblastoma cells. In vivo biodistribution of these nanocomplexes was investigated in small animals.

\section{Methodologies}

\subsection{Materials}

The curcumin $\left(\mathrm{C}_{21} \mathrm{H}_{20} \mathrm{O}_{6}\right)$ and Poly(D,L-lactide-co-glycolide) (Mw 30-60 kDa, lactide:glycolide 50:50) were purchased from Sigma-Aldrich, Saint Louis, MO, USA. Dichloromethane $\left(\mathrm{CH}_{2} \mathrm{Cl}_{2}\right.$, SRL, Chennai, India), tetrahydrofuran $\left(\mathrm{C}_{4} \mathrm{H}_{8} \mathrm{O}\right.$, Alfa Aesar, Haverhill, MA, USA, 99.99\% purity), ethanol $\left(\mathrm{C}_{2} \mathrm{H}_{5} \mathrm{OH}, 99.99 \%\right.$ purity), sodium fluoride (NaF, Chennai, India, 99\%), yttrium nitrate $\mathrm{Y}\left(\mathrm{NO}_{3}\right)_{3} \cdot 6 \mathrm{H}_{2} \mathrm{O}$ (Alfa Aesar, Haverhill, MA, USA, 99.99\%), ytterbium nitrate $\left(\mathrm{Yb}\left(\mathrm{NO}_{3}\right)_{3} \cdot 6 \mathrm{H}_{2} \mathrm{O}\right.$, Alfa Aesar, Haverhill, MA, USA, 99.99\%), erbium nitrate $\left(\mathrm{Er}\left(\mathrm{NO}_{3}\right)_{3} \cdot 5 \mathrm{H}_{2} \mathrm{O}\right.$, Alfa Aesar, Haverhill, MA, USA, 99.99\%), thulium nitrate $\left(\mathrm{Tm}\left(\mathrm{NO}_{3}\right)_{3} \cdot 6 \mathrm{H}_{2} \mathrm{O}\right.$, Alfa Aesar, Haverhill, MA, USA, 99.99\%), isooctane (SRL, Chennai, India 99.8\%), oleic acid (OA, Sigma-Aldrich, Saint Louis, MO, USA, 90\%), cetyltrimethylammonium bromide (CTAB) (Sigma-Aldrich, Saint Louis, MO, USA, 95\%), 1-butanol (Vetec, Sigma-Aldrich, Saint Louis, MO, USA, $\geq 99.5 \%$ ), and acetone (Rankem, Mumbai, India, 99\%) were used in the synthesis of UCNPs. All chemicals and solvents are in analytical purity.

\subsection{Preparation of Nanocurcumin}

Nanocurcumin was synthesized using the evaporation-assisted solvent-antisolvent method in the Optical Nanomaterials Laboratory, Department of Nuclear Physics, University of Madras, Chennai, India. Tetrahydrofuran (THF) was chosen as solvent and distilled water act as antisolvent. The $0.1 \mathrm{~g}$ of curcumin was dissolved with 1:10 ratio of THF and distilled water. The sample was stirred for $20 \mathrm{~min}$ to acquire homogeneous solution. Subsequently, the resultant mixture was subjected to ultra-sonication $(20-20,000 \mathrm{kHz})$ in the water bath-sonication for $150 \mathrm{~min}$ to produce an emulsion and rapidly stirred for $30 \mathrm{~min}$. The supernatant was decanted and a thick residue was air-dried by $80{ }^{\circ} \mathrm{C}$ heating to about $3 \mathrm{~h}$.

\subsection{Preparation of Nanocurcumin Loaded UCNPs by PLGA Polymer}

To prepare UCNP1-PLGA-nanocur composite, the hexagonal $\mathrm{NaYF}_{4}: 20 \% \mathrm{Yb}, 2 \% \mathrm{Er}$ UCNPs was synthesized by reverse microemulsion method based on the earlier reports with a minor alteration in calcination temperature of $550{ }^{\circ} \mathrm{C}$ [23]. Further, the drug loading process was done based on the molecular interaction method. A weighed amount of $80 \mathrm{mg}$ of $\mathrm{NaYF}_{4}: \mathrm{Yb}$,Er-550 ${ }^{\circ} \mathrm{C}$ (UCNP1) nanoparticles and biocompatible polymer PLGA (50:50) taken with an amount of $25 \mathrm{mg}$ be liquefied in dichloromethane (DCM) under mild stirring. 
Then, $50 \mathrm{mg}$ of nanocurcumin was added with the above polymeric solution, and the yellowish solution was stirred vigorously. The concentration of PLGA is kept low to avoid the upconversion emission quenching by polymer functional groups. Then, the suspension was stirred well for $4-5 \mathrm{~h}$ continuously to allow the drug molecules to dissolve and be adsorbed on the UCNPs. Later, after the homogenization, the combined DCM/organic phases are evaporated. Further, the precipitated sample was obtained by washing with ethanol. The supernatant was isolated by filtration from the drug loaded nanocarrier to measure the amount of free drug. Finally, the sample was air dried overnight without any heating to avoid degradation of the polymer. The collected yellowish orange solid of nanocurcumin drug loaded samples were characterized. Similarly, to synthesis the UCNP2PLGA-nanocur composite, $\mathrm{NaYF}_{4}: \mathrm{Yb}, \mathrm{Tm}$ was prepared by doping $2 \%$ of $\mathrm{Tm}\left(\mathrm{NO}_{3}\right)_{3} \cdot 6 \mathrm{H}_{2} \mathrm{O}$ on the contrary to $2 \%$ of $\mathrm{Er}\left(\mathrm{NO}_{3}\right)_{3} \cdot 6 \mathrm{H}_{2} \mathrm{O}$ and calcined at $550{ }^{\circ} \mathrm{C}$ for $30 \mathrm{~min}$. Then, $25 \mathrm{mg}$ of biocompatible polymer PLGA (50:50) and $80 \mathrm{mg}$ of nanocurcumin was added in DCM under stirring to conjugate the UCNPs. All the above upconversion nanomaterials were prepared in Optical Nanomaterials Laboratory (J.S. Lab.), Department of Nuclear Physics, University of Madras, Chennai, India,

\subsection{Materials Characterizations}

In order to analyse the crystal structural phase of the UCNPs and nanocurcumin drug loaded UCNP samples, powder X-ray diffraction (XRD) study was carried out with the BRUKER D8 ADVANCE X-ray Diffraction platform (Karlsruhe, Germany) at $\mathrm{Cu} \mathrm{K} \alpha 1 \mathrm{X}$-ray wavelength of $0.15406 \mathrm{~nm}$. The X-ray diffraction data was collected in the two-theta range from 5 to $65^{\circ}$ at a scanning rate $0.03 \mathrm{~s}^{-1}$. XRDA software (version 3.1, http://ccp14.cryst.bbk.ac.uk/ccp/ccp14/ftp-mirror/xrda/pub/lpsd/, accessed on $16 \mathrm{Au}$ gust 2021) was used for the diffraction profile fitting analysis. The surface morphology of the UCNP, UCNP-PLGA and UCNP-PLGA-Nanocurcumin was examined by High Resolution Scanning Electron Microscope (FEI Quanta FEG 200F, Hillsboro, OR, USA). Image J software (https:/ /imagej.nih.gov/ij/download.html, accessed on 16 August 2021) was employed to calculate the particle size. Energy Dispersive X-ray spectroscopy Analysis (EDAX) and elemental mapping of NaYF4:Yb,Er-PLGA-Nanocurcumin complex was performed using the ZEISS Field Emission Scanning Electron Microscope (GeminiSEM 300, Oberkochen, Germany), which equipped with EDX detector (ULTIM MAX Silicon Drift Detector, OXFORD INSTRUMENTS, High Wycombe, United Kingdom), and the results are provided in the Supplementary Information. The thermal behaviour of the raw-curcumin and synthesized nanocurcumin was explored by Differential Thermal Analysis (DTA) and the temperature dependent weight change property was studied by Thermogravimetric analysis (TGA) by heating the sample from room temperature to $500{ }^{\circ} \mathrm{C}$ at a scanning rate $10{ }^{\circ} \mathrm{C} \mathrm{min}{ }^{-1}$ using the TGA-DTA Thermal Analyser (STA 2500 Regulus Simultaneous Thermal Analysis system, NETZSCH, Selb, Germany) under the nitrogen atmosphere, the results are given in Supplementary Information. The chemical functional group analyses of the samples were investigated by employing the Bruker FTIR Spectrometer ALPHA II (Ettingen, Germany) in the infrared absorption frequency range $500-4000 \mathrm{~cm}^{-1}$. Raman spectra of the UCNPs, UCNP-PLGA and UCNP-PLGA-Nanocurcumin samples were explored by interacting the samples with diode pumped solid state laser at $532 \mathrm{~nm}$ using the Horiba Jobin Yvon XPloRA Plus Raman Microscope (Horiba Techno Service, Ltd., Kyoto, Japan) in the spectroscopic mode. Optical absorption of the as-received curcumin and the solvent-antisolvent synthesized nanocurcumin was studied using the Analytik Jena UV-VIS spectrometer (Specord 210 Plus, Jena, Germany) and the spectral results are given in the Supplementary Information. Photoluminescence behaviour of curcumin and nanocurcumin was studied with HORIBA FluoroMax Plus spectrofluormeter (Techno Service Co., Ltd., Kyoto, Japan) by exciting the samples at $424 \mathrm{~nm}$ wavelength and the emission results are provided in the Supplementary Information. The hand-held $200 \mathrm{~mW}$ $980 \mathrm{~nm}$ infrared diode laser pointer was employed to check upconversion emission at each stage of sample preparation. For the detailed investigation of the upconversion emission 
characteristics of the UCNP, UCNP-PLGA and UCNP-PLGA nanocomplexes, we employed the sophisticated Quanta Master 51 spectrofluorometer (Photon Technology International Inc., Birmingham, NJ, USA) and $980 \mathrm{~nm}$ laser excitation source (Spectra Physics, Model 3900S, Milpitas, CA, USA). The down converting NIR fluorescence was recorded by InGaAs detector (Teledyne Judson Technologies, 062-8451, Montgomeryville, PA, USA). Zeta potential of the UCNP, UCNP-PLGA and UCNP-PLGA-Nanocurcumin was measured the HORIBA Nanoparticle Analyzer (nanoPARTICA SZ-100, Horiba, Ltd., Kyoto, Japan), and the results are available in the "Supplementary Information". The ChemSpider free online chemical structure database (https: / / www.chemspider.com/StructureSearch.aspx, accessed on 16 August 2021) was employed to draw the chemical structure of THF, PLGA and curcumin.

\subsection{Biomedical Investigation}

\subsubsection{Cell Culture}

Rat glioma C6 cells were cultivated in Dulbecco's Modified Eagle Medium (DMEM). To make the complete medium, it was supplemented with $10 \%$ foetal bovine serum (FBS), $2 \mu \mathrm{M}$ L-glutamine, and a combination of streptomycin $(100 \mu \mathrm{g} / \mathrm{mL})$ and penicillin $(100 \mathrm{U} / \mathrm{mL})$ antibiotics. Cells were grown at $37{ }^{\circ} \mathrm{C}$ in a $5 \% \mathrm{CO}_{2}$ humidified atmosphere and passaged every 2-3 days at $80-90 \%$ confluence. Passaging was performed with $0.25 \%$ Trypsin-EDTA solution, and the subcultivation ratio was $1: 3$ to $1: 6$ according to ATCC recommendations.

\subsubsection{Cytotoxicity in Monolayer Culture (MTT Assay)}

Rat C6 glioma cells $\left(5 \times 10^{3}\right)$ were placed on a 96-well flat bottom plate and incubated for a night at $37^{\circ} \mathrm{C}$ in a $5 \% \mathrm{CO}_{2}$ humidified atmosphere. UCNPs were suspended in full DMEM just prior to the experiment and added to the cells to the final concentrations of $0.02-0.8 \mathrm{mg} / \mathrm{mL}$ for $48 \mathrm{~h}$. After that, MTT (3-(4,5-dimethylthiazol-2-yl)2,5-diphenyltetrazolium bromide) solution $(0.5 \mathrm{mg} / \mathrm{mL})$ was added to the cells for $3 \mathrm{~h}$. Then, MTT solution was removed and replaced with $100 \mu \mathrm{L}$ of DMSO. The absorbance of the dissolved formazan was measured with a microplate reader (Multiscan, Thermo FS, Massachusetts, United States of America) at a wavelength of $570 \mathrm{~nm}$ according to the manufacturer's protocol. All measurements were performed in three independent replicates, and the final data were indicated as average $\pm S D$, and the absorbance of the non-treated (control) cells was taken as $100 \%$.

\subsubsection{Cytotoxicity in Tumor Spheroids (MTS Assay)}

Tumour spheroids were obtained using liquid overlay technique as per the previous report [27]. For this, we resuspended 1.5\% wt of agarose in PBS (pH 7.4) and heated the mixture in water bath for 15 min that resulted in agarose melting and sterilization. After that, we placed $100 \mu \mathrm{L}$ of agarose solution to a flat-bottom 96-well plate under sterile conditions. Then, plates with agarose were cooled down to room temperature for $15 \mathrm{~min}$, which led to agarose solidification and non-adhesive surface formation. We seeded rat C6 glioma cells onto obtained agarose-coated plates $(10,000$ cells/well in $100 \mu \mathrm{L}$ of full DMEM) and incubated for $72 \mathrm{~h}$ in standard culture conditions to generate spheroids. After that, UCNPs suspensions in full DMEM were added to spheroids to the final concentration of $0.12-0.8 \mathrm{mg} / \mathrm{mL}$ for $48 \mathrm{~h}$. The cytotoxicity was evaluated using colorimetric MTS assay. For this, we added $10 \mu \mathrm{L}$ of MTS reagent per well and incubated for $3 \mathrm{~h}$ at $37^{\circ} \mathrm{C}$, and the soluble formazan was measured at $490 \mathrm{~nm}$ with a microplate reader (Multiscan, Thermo FS, Massachusetts, United States of America) according to the manufacturer's protocol.

2.5.4. Intracellular Accumulation (Anti-Stokes Photoluminescence Microscopy and Confocal Fluorescence Microscopy)

Rat glioma C6 cells $\left(5 \times 10^{4}\right)$ were seeded on an 8 -well glass chamber slide and incubated overnight. Then, UCNPs were suspended in full DMEM to $0.05 \mathrm{mg} / \mathrm{mL}$ and added to the cells for $1 \mathrm{~h}$. After that, the cells were thoroughly rinsed three times with 
sterile PBS (pH 7.4) and finally fixed using 4\% formaldehyde solution. For fluorescence microscopy, the cell nuclei were additionally stained with doxorubicin (100 $\mu \mathrm{M}, 10 \mathrm{~min})$. The excitation wavelength for nanocurcumin was $488 \mathrm{~nm}$, and the emission signal was collected in 500-600 nm.

\subsubsection{Live-Dead Assay on Tumour Spheroids (Confocal Microscopy)}

Tumour spheroids were generated as it was described above. Then, the spheroids

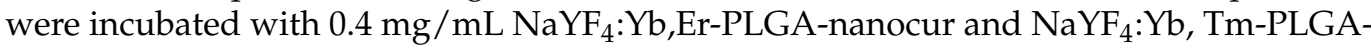
nanocur for $48 \mathrm{~h}$. Spheroids were stained with Calcein AM $(50 \mu \mathrm{M})$ and Propidium Iodide $(25 \mu \mathrm{M})$ for $30 \mathrm{~min}$ at $37^{\circ} \mathrm{C}$ in a $5 \% \mathrm{CO}_{2}$ humidified atmosphere. Stained spheroids were rinsed with PBS (pH 7.4), mounted on a glass slide, and analysed using Leica TSP SPE confocal microscope.

\subsubsection{Accumulation in Tumour Spheroids (Confocal Microscopy)}

Tumour spheroids were generated as it was described above. Then, the spheroids were incubated with $0.4 \mathrm{mg} / \mathrm{mL} \mathrm{NaYF}_{4}: \mathrm{Yb}$,Er-PLGA-nanocur and $\mathrm{NaYF}_{4}: \mathrm{Yb}$,Tm-PLGA-nanocur for $2 \mathrm{~h}$ and $48 \mathrm{~h}$. Then, spheroids were washed with PBS (pH 7.4), mounted on a glass slide, and analysed using Leica TSP SPE confocal microscope. The excitation wavelength for nanocurcumin was $488 \mathrm{~nm}$, and the emission signal was collected in 500-600 nm.

\subsubsection{Animal Experiments}

The experimental animals (female BDF1 mice) were kept under controlled environmental conditions, in particular constant temperature, humidity, and a $12 \mathrm{~h}$ dark-light cycle. They were allowed free access to water and mouse chow. All animal experiments were performed in accordance with European and Russian national guidelines for animal experimentation, and animal experiments were approved by the local animal and ethics review committee of the FSBSI "N.N. Blokhin Russian Cancer Research Center".

\subsubsection{Biodistribution In Vivo}

The experiments were carried out on female BDF1 mice (C57Bl/ $6 \times$ DBA2). Before the UCNPs administration, mice were pre-anesthetized with a combination Zoletil 100 ( $2.5 \mathrm{mg} / \mathrm{kg}$ tiletamine hydrochloride and $2.5 \mathrm{mg} / \mathrm{kg}$ zolazepam hydrochloride) (Virbac, Caro, France) and Rometar (xylazine hydrochloride $0.2 \mathrm{mg} / \mathrm{kg}$ ) (SPOFA, Markova, Czech Republic) intraperitoneally, $150 \mu \mathrm{L} /$ mouse. The drug was administered intravenously through the retro-orbital sinus at a dose of $0.75 \mathrm{mg} / \mathrm{mouse}(30 \mathrm{mg} / \mathrm{kg})$. Mice were sacrificed by instantaneous dislocation of the cervical vertebrae in the cranio-cervical direction $4 \mathrm{~h}$ and $24 \mathrm{~h}$ after intravenous administration. Post-mortem parenchymal organs were exterminated and images were obtained.

\subsubsection{Lewis Lung Cancer Mouse Model}

Lewis lung cancer $(\mathrm{LLC})$ model BDF1 $(\mathrm{C} 57 \mathrm{Bl} / 6 \times \mathrm{DBA} 2)$ mice was proposed to evaluate the UCNPs accumulation in tumours in vivo. For this, LLC was extracted from BDF1 mice (day 11 after grafting) and subcutaneously inoculated into experimental mice (0.3 mL LLC in DMEM suspension 1:10). After two weeks, the UCNP suspension (0.75 mg in $150 \mu \mathrm{L}$ ) was injected into the mice peritumorally. Images were obtained from the DVS-02 imaging system $24 \mathrm{~h}$ after administration.

\section{Results and Discussion}

\subsection{Nanocurcumin-Loaded UCNPS Preparation}

Figure 1a,b depicts the schematic synthesis of UCNP1-PLGA-nanocurcumin and UCNP2-PLGA-nanocurmin. The loading of nanocurcumin into UCNP involved three stages. Firstly, nanocurcumin was prepared by using the solvent-evaporation assisted solvent-antisolvent method using THF and distilled water. It showed absorbance at $425 \mathrm{~nm}$ and emission at $560 \mathrm{~nm}$ (Figure S1a,b; detailed discussion is given in the supplementary 
information). The sample was collected after solvent evaporation by sonication and airdried at $80^{\circ} \mathrm{C}$ to remove water moiety, which is confirmed through the TGA and DTA results shown in Figure S2a,b. In the second step, $\mathrm{NaYF}_{4}: \mathrm{Yb}, \mathrm{Er}(\mathrm{UCNP} 1)$ and $\mathrm{NaYF}_{4}: \mathrm{Yb}, \mathrm{Tm}$ (UCNP2) nanoparticles were synthesized utilizing the reverse micro-emulsion process with strategy of surfactant/water/oil phase solvents. It yielded spherical nanospheres suitable to load the nanocurcumin. Finally, UCNP1-PLGA-nanocur and UCNP2-PLGA-nanocur composites were prepared by facile molecular interaction approach. The PLGA was used to encapsulate the nanocurcumin into UCNPs to improve the surface properties by interacting with the carboxylic groups of the polymer [20,28].

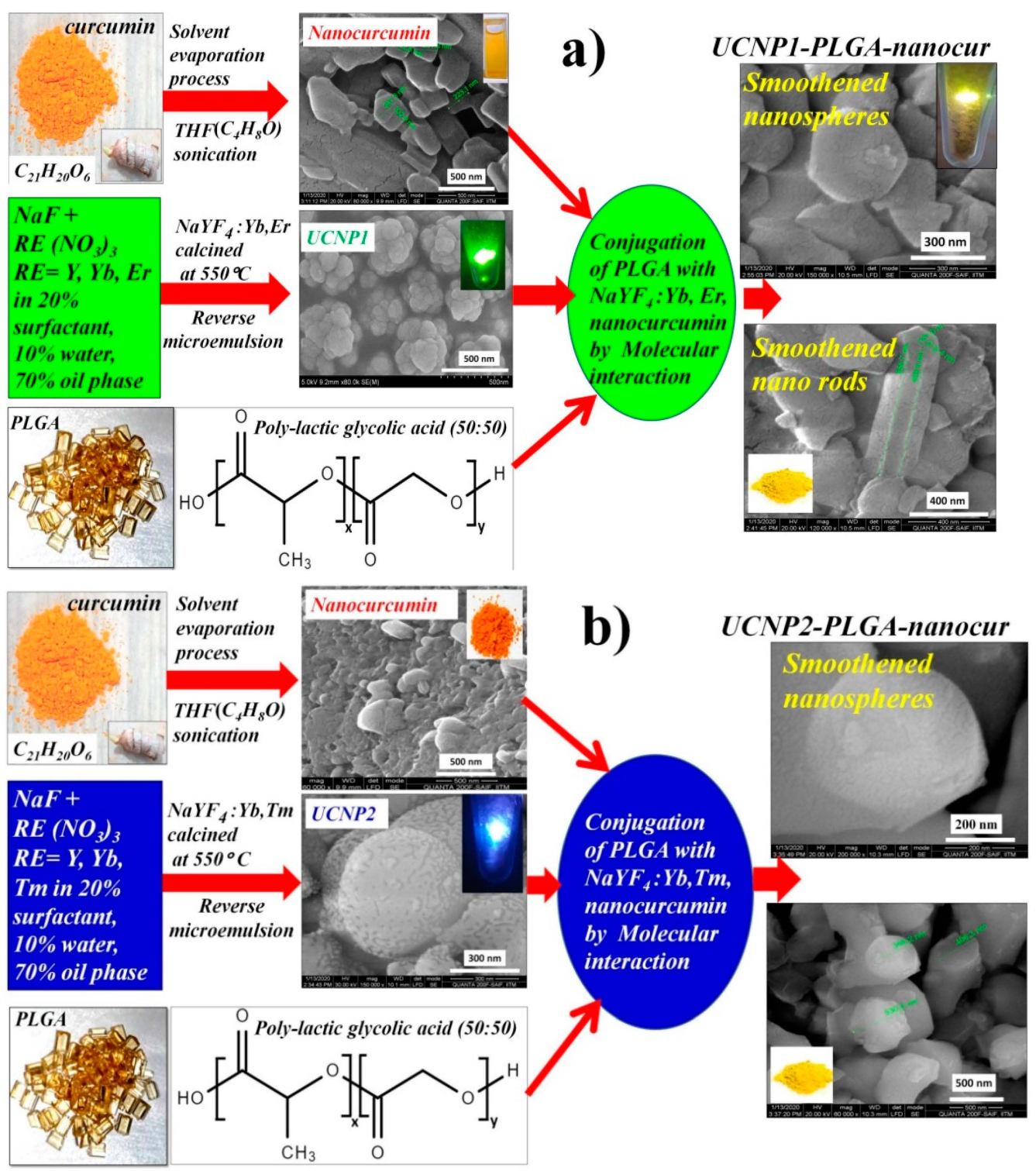

Figure 1. Formation mechanism of (a) UCNP1-PLGA-nanocur, (b) UCNP2-PLGA- nanocur.

\subsection{HRSEM Analysis}

Figure 2a-j shows the HRSEM images of nanocurcumin $(a, b)$, UCNP1(c,d), UCNP1PLGA nanocur (e,f), UCNP2 (g,h) and UCNP2- PLGA-nanocur $(\mathrm{i}, \mathrm{j})$. Figure $2 \mathrm{a}, \mathrm{b}$ represents the morphological behaviour of nanocurcumin and the particle size is $150-200 \mathrm{~nm}$. Reverse microemulsion synthesized UCNP1 (Figure 2c,d) and UCNP2 (Figure 2g,h) are formed as spherical nanoclusters in size $\sim 200-300 \mathrm{~nm}$. Figure $2 \mathrm{e}, \mathrm{f}$ shows the surface morphology of nanocurcumin-loaded UCNP1-PLGA, which shows nanospheres in size $\sim 300 \mathrm{~nm}$. Figure $2 \mathrm{i}, \mathrm{j}$ shows that UCNP2-PLGA-nanocur with the size of $\sim 350 \mathrm{~nm}$. SEM-EDAX analy- 
sis was performed for finding the chemical species present in the UCNP1-PLGA-nanocur composite. The EDAX spectrum shown in Figure S3a-c explores the existence of $\mathrm{Yb}$ and Er dopant ions and host material elements $\mathrm{Na}, \mathrm{Y}$ and $\mathrm{F}$ in the UCNP1-PLGA-nanocur composite. The detailed analysis on the EDAX spectrum is included in the supplementary information. Figure S4 displays the elemental mapping and distribution of the $\mathrm{Na}, \mathrm{Y}, \mathrm{F}$, $\mathrm{Yb}, \mathrm{Er}, \mathrm{C}$, and $\mathrm{O}$. The upconversion nanoparticles are considered as attractive drug carriers because of their remarkable benefits of increased tumour-specific targeting ability and minimal side effects along with superior drug loading capability [29]. It is reported that the sphericity plays a major role in drug releasing properties $[28,30]$ and particle size is an essential criterion in drug delivery [2]. The large-sized PLGA copolymer functionalized UCNP could effectively encapsulate the drug and increase drug loading [31]. The large and porous structured UCNP could promote drug loading ability [29,32]. To analyse the stability of UCNP and nanocurcumin, their zeta potential was measured by dynamic light scattering method and the results are given Figure S5 and Table S1.

\subsection{X-ray Diffraction Analysis}

At each stage of the preparation process, for the structural phase determination of UCNPs and drug encapsulated UCNPs, the X-ray powder diffraction was employed. Figure 3a reveals the XRD patterns of nanocurcumin, UCNP1 and UCNP1-PLGA-nanocur, respectively. Figure $3 \mathrm{~b}$ displays the XRD spectrum of UCNP2 and UCNP2-PLGA-nanocur, respectively. The diffraction patterns of the synthesized nanocurcumin exhibits five distinctive peaks at $12.21,17.13,24.59,25.58$ and $26.23^{\circ}$ in the two-theta range of 10 to $30^{\circ}$. The result is consistent with the JCPDS: 09-0816 as can be verified in Figure 3a. It implies the synthesized nanocurcumin is formed in crystalline form [33]. The diffraction peaks of reverse micro-emulsion synthesized UCNP1 and UCNP2 are matches well the JCPDS:16-0334 of hexagonal $\beta-\mathrm{NaYF}_{4}$. The hexagonal phase UCNP1 and UCNP2 are crystalline with the space group of $\mathrm{p} 63 / \mathrm{m}$ [5]. The diffraction peaks of the UCNP1-PLGA-nanocur and UCNP2PLGA-nanocur broaden with a decrement in their peak intensity compared to UCNP1 and UCNP2, and it can be identified at 29 and $30^{\circ}$ corresponding to the (110) and (101) planes. The broad peak indicates the incorporation of nanocurcumin with UCNPs. It is also noticed that in the XRD pattern of UCNP1-PLGA-nanocur and UCNP2-PLGA-nanocur, the intense and sharp characteristic diffraction peaks related to nanocurcumin did not appear from 5 to $30^{\circ}$. The absence of nanocurcumin peaks is due to the dominated hexagonal structure of UCNPs in the UCNP1-PLGA-nanocur and UCNP2-PLGA-nanocur samples [14]. Even after the addition of PLGA and nanocurcumin drug loading, the hexagonal UCNP is stable. This is advantageous for biomedical applications. The lattice parameters and cell volume is given in Table 1, The diffraction pattern of nanocurcumin and PLGA encapsulated UCNPs nanoparticles is slightly broadened compared to UCNP1 and UCNP2 owing to the polymer. This result is comparable with the XRD pattern of PLGA 50:50 nanoparticles reported by Mahajan et al. [34].

\subsection{FTIR Absorption Spectroscopy}

The FTIR spectra of nanocurcumin, $\mathrm{NaYF}_{4}: \mathrm{Yb}, \mathrm{Er}(\mathrm{UCNP})$ and UCNP-PLGA-nanocur samples are displayed in Figure 4. The nanocurcumin shows a weak peak at $717 \mathrm{~cm}^{-1}$ allocated for the $\mathrm{C}-\mathrm{H}$ vibrations of the aromatic ring [14]. The other peaks at $816 \mathrm{~cm}^{-1}$ and $857 \mathrm{~cm}^{-1}$ correspond to the $\mathrm{C}-\mathrm{H}$ bending [33]. The peak at $958 \mathrm{~cm}^{-1}$ is allotted for the benzoate trans- $\mathrm{C}-\mathrm{H}$ vibration [14]. The other peak at $1020 \mathrm{~cm}^{-1}$ may be attributed for $\mathrm{C}-\mathrm{O}-\mathrm{C}$ groups [33] and peak at $1149 \mathrm{~cm}^{-1}$ is assigned to the functional group of $\mathrm{C}-\mathrm{H}$ stretching [11]. Then peak at $1277 \mathrm{~cm}^{-1}$ represent the $\mathrm{C}-\mathrm{O}$ stretching group and the peak at $1429 \mathrm{~cm}^{-1}$ corresponds to phenolic $\mathrm{C}-\mathrm{O}$ stretching [35].The absorption peak seen at $1497 \mathrm{~cm}^{-1}$ is assigned to the $\mathrm{C}=\mathrm{O}$ and $\mathrm{C}=\mathrm{C}$ vibrations [36]. The strong absorption peak that arises from $1598 \mathrm{~cm}^{-1}$ can be denoted for the symmetric stretching vibrations about the aromatic ring $\left(C=C\right.$ ring) [17]. Another absorption peak noticed at $1632 \mathrm{~cm}^{-1}$ might be due to the $(\mathrm{C}=\mathrm{C})$ stretching [11]. The peak located around $\sim 3505-3510 \mathrm{~cm}^{-1}$ expresses that there 
is presence of $\mathrm{OH}$ stretching in the glucose moiety in the nanocurcumin. The presences of all the characteristics peaks of nanocurcumin in the FTIR spectrum suggest that there is no chemical alteration or notable degradation of the drug during the solvent-antisolvent process $[14,16,33,36]$.
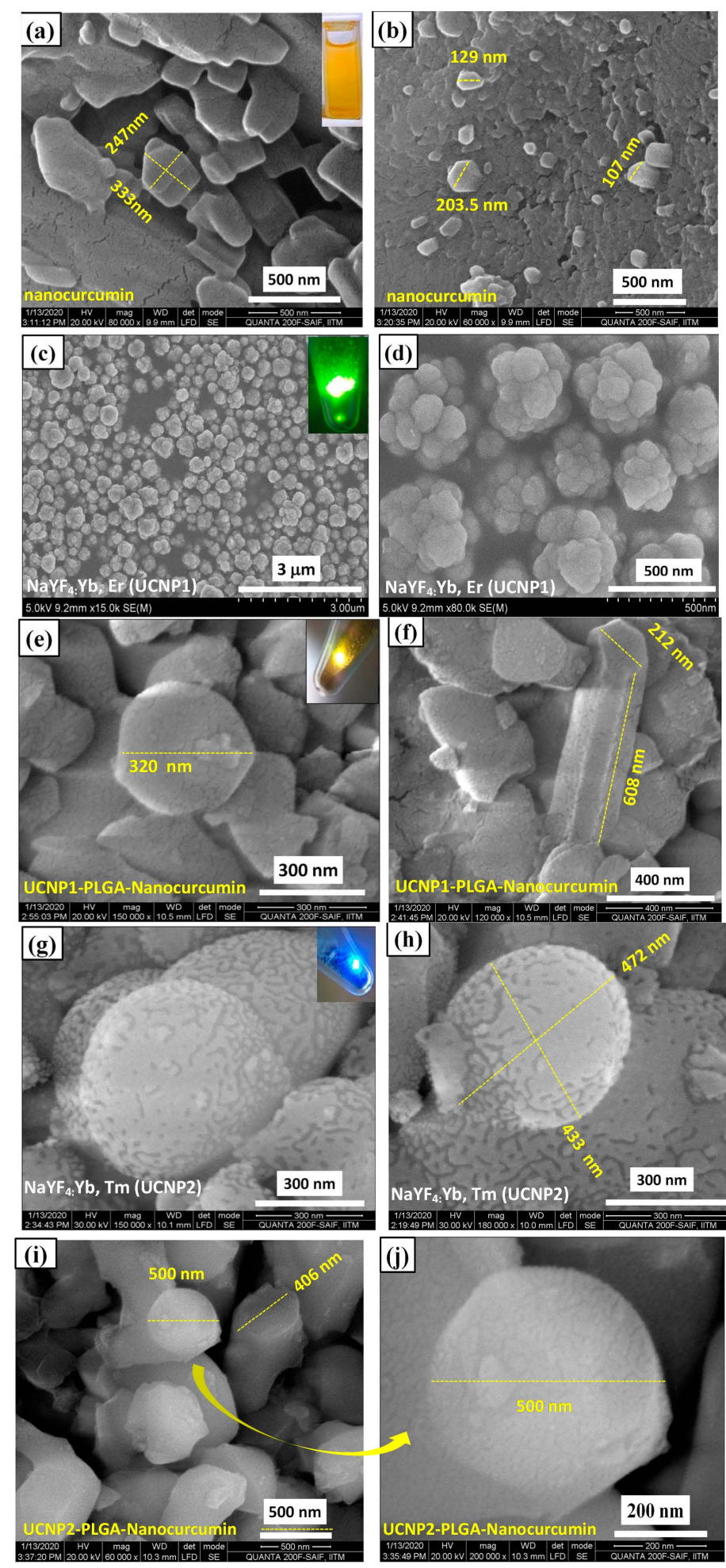

Figure 2. HRSEM images of nanocurcumin (a,b), UCNP1 (c,d), UCNP1-PLGA-nanocur (e,f), UCNP2 $(\mathrm{g}, \mathbf{h})$, and UCNP2-PLGA-nanocur $(\mathbf{i}, \mathbf{j})$. 

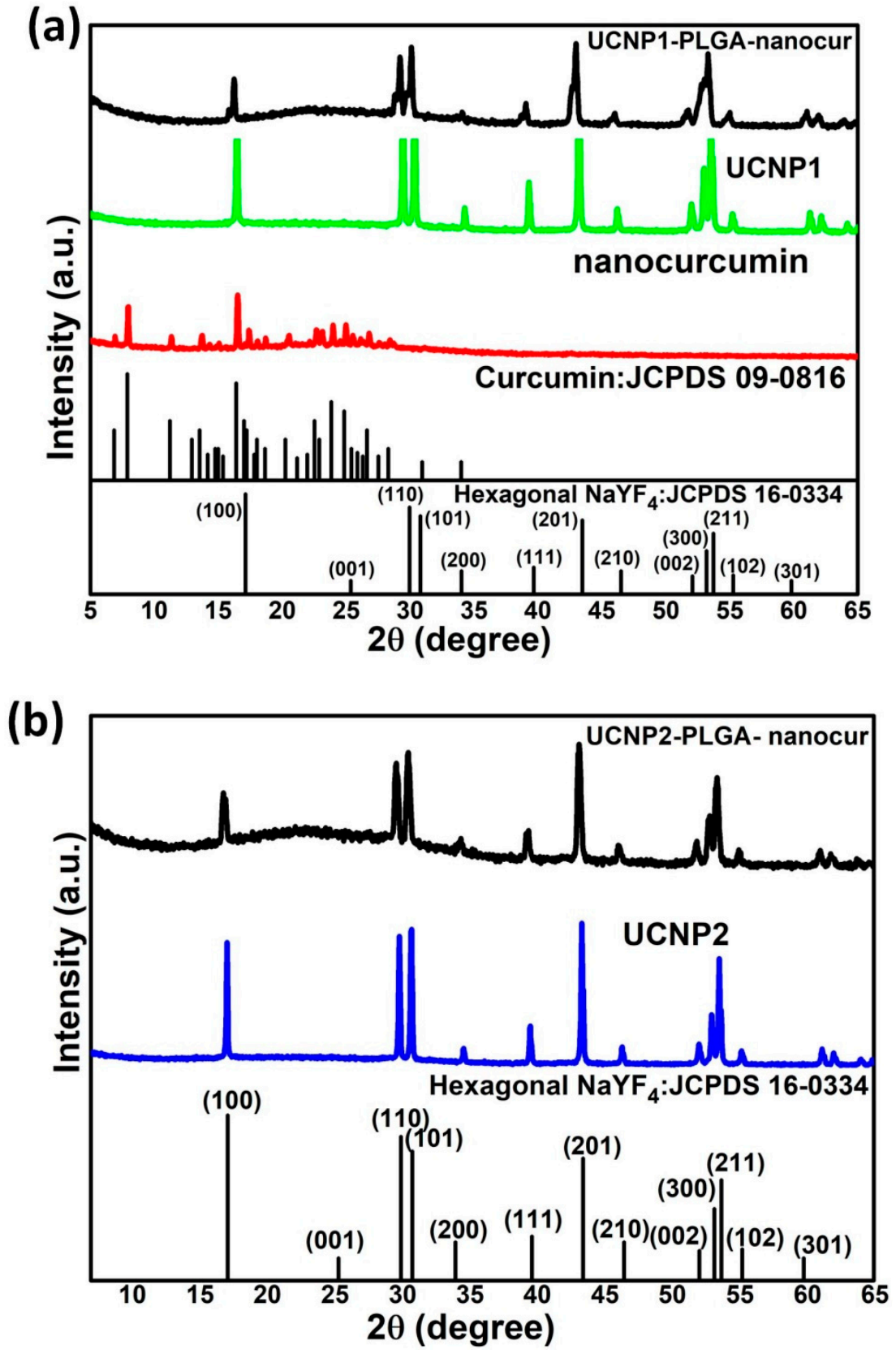

Figure 3. XRD patterns of (a) $\mathrm{NaYF}_{4}: \mathrm{Yb}, \mathrm{Er}$ (UCNP1), nanocurcumin, UCNP1-PLGA-nanocur (b) $\mathrm{NaYF}_{4}: \mathrm{Yb}, \mathrm{Tm}(\mathrm{UCNP} 2)$, and UCNP2-PLGA-nanocur.

Table 1. The lattice parameters of UCNP and the UCNP-PLGA-nanocurcumin complexes.

\begin{tabular}{cccc}
\hline Sample & Crystal Structure & Lattice Parameters $(\AA)$ & Volume $\left(\AA^{3}\right)$ \\
\hline UCNP1 & hexagonal NaYF & $\mathrm{a}=5.9404 ; \mathrm{c}=3.5063$ & 107.508 \\
\hline UCNP1-PLGA-nanocur & hexagonal NaYF & $\mathrm{a}=6.015 ; \mathrm{c}=3.5120$ & 110.041 \\
\hline UCNP2 & hexagonal NaYF & $\mathrm{a}=5.9806 ; \mathrm{c}=3.5113$ & 108.764 \\
\hline UCNP2-PLGAnanocur & hexagonal NaYF & $\mathrm{a}=6.0495 ; \mathrm{c}=3.5144$ & 111.383 \\
\hline JCPDS No.16-0334 & hexagonal NaYF & $\mathrm{a}=5.96 ; \mathrm{c}=3.51$ & 107.974 \\
\hline
\end{tabular}




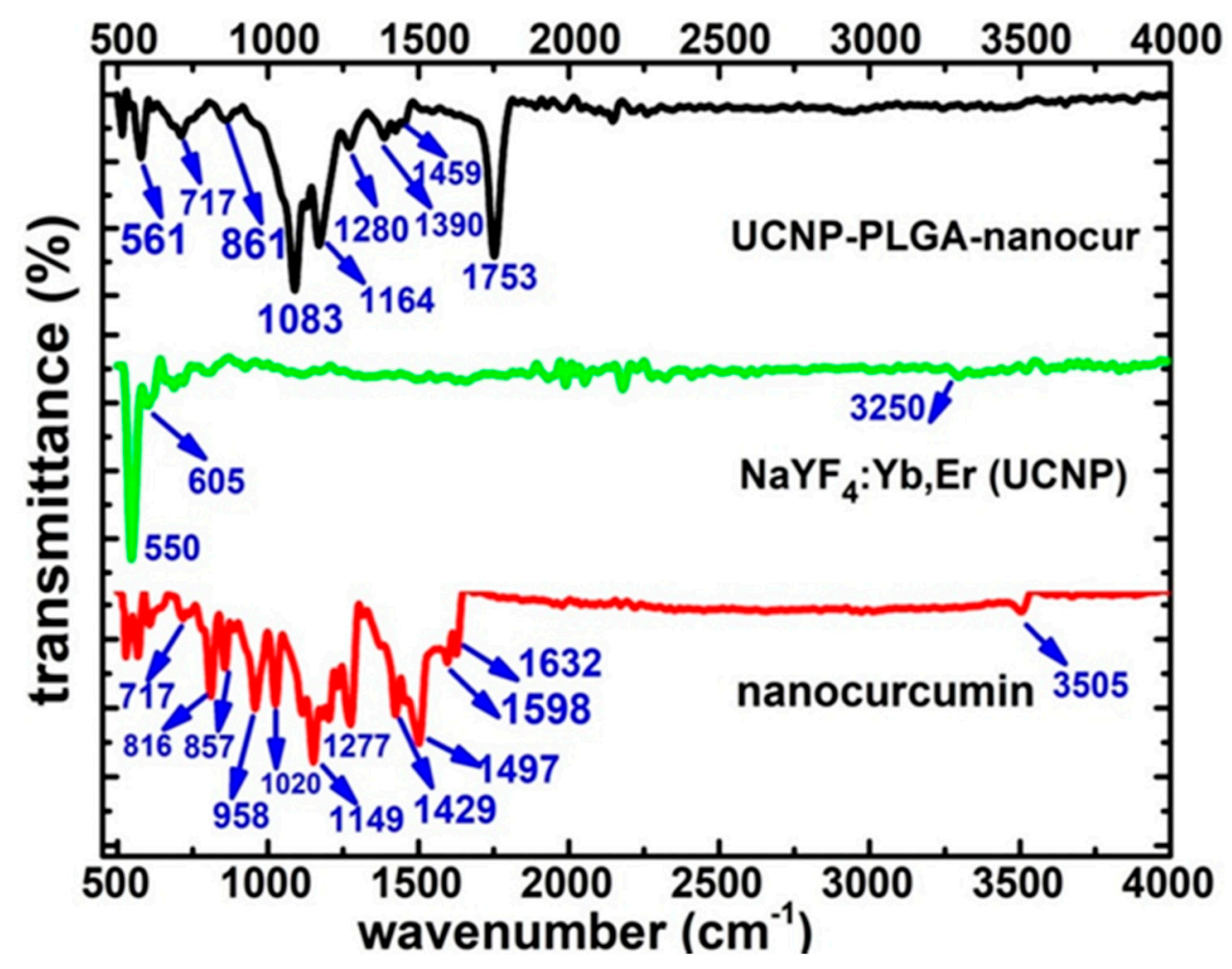

Figure 4. FTIR spectra of nanocurcumin, $\mathrm{NaYF}_{4}: \mathrm{Yb}$,Er and UCNP-PLGA-nanocur.

$\mathrm{NaYF}_{4}: \mathrm{Yb}$,Er (UCNP) exhibits a strong absorption peak around $550 \mathrm{~cm}^{-1}$ and small absorption peak at $605 \mathrm{~cm}^{-1}$ which corresponds to stretching vibrations of metal fluorides. An absorption peak observed at $3250 \mathrm{~cm}^{-1}$ represent the stretching vibration of the amine groups $\left(-\mathrm{NH}_{2}\right)$ of $\mathrm{CTAB}$ (capping ligand) surfactant prepared by the reverse micro-emulsion method. Hence, the contribution of the amine surfactant moieties improves the biocompatibility and the hydrophilic property of the drug carrier [5].

Whereas, the FTIR spectrum of UCNP-PLGA-nanocur exhibits the existence of functional groups present in the nanocurcumin and UCNPs. Among these, the characteristic functional groups of nanocurcumin at 717,861, and $1280 \mathrm{~cm}^{-1}$ could be identified from the drug incorporated sample. Particularly, the absorption peaks for the nanocurcumin around 861 and $1280 \mathrm{~cm}^{-1}$ experienced a mild shift to 857 and $1277 \mathrm{~cm}^{-1}$ in the drug loaded sample due to nano-encapsulation and indicates successful drug loading. Similarly, the identified metal fluoride functional group of UCNPs at $550 \mathrm{~cm}^{-1}$ also involved with slight shift to $561 \mathrm{~cm}^{-1}$ owing to the interaction between drug and UCNPs. In addition, $\mathrm{C}-\mathrm{O}-$ stretch of $\mathrm{C}-\mathrm{O}-\mathrm{H}$ groups rose in $1083 \mathrm{~cm}^{-1}$ and also the absorption peak occurring at 1459 denoted for the $\mathrm{C}-\mathrm{O}-\mathrm{H}$ in plane bending of carboxylic acid $(-\mathrm{COOH})$ [31]. It is to be noted that the new strong absorption peak arises from $\sim 1753 \mathrm{~cm}^{-1}$, which might signify the characteristic $\mathrm{C}=\mathrm{O}$ stretching of acid group due to the interaction of PLGA polymer $[25,30]$. The small absorption peaks at 1164 and $1280 \mathrm{~cm}^{-1}$ indicate the $\mathrm{C}-\mathrm{O}$ stretching. The other absorption peaks found at 1390 and $1459 \mathrm{~cm}^{-1}$ are assigned to $\mathrm{O}-\mathrm{H}$ bending vibrations and $\mathrm{C}-\mathrm{H}$ bending, $\mathrm{C}=\mathrm{C}$ stretching vibrations for the aromatic ring independently. It affirms that the nanocurcumin efficiently loaded with UCNPs via PLGA ligands attached on the surface of the nanocarrier. The PLGA functionalization with carboxylic groups could improve the binding affinity between the nanocurcumin drug and the UCNP nanocarrier, which will be useful for drug delivery applications [5].

\subsection{Raman Spectroscopy}

Figure 5a,b shows the Raman spectra recorded for nanocurcumin, UCNP1, UCNP1PLGA-nanocur and UCNP2, UCNP2-PLGA-nanocur. The Raman vibrational modes of the nanocurcumin are located from $950 \mathrm{~cm}^{-1}$ to $1700 \mathrm{~cm}^{-1}$ as shown in Figure $5 \mathrm{a}$, and the 
results were in concurrence to the reported data [37]. The Raman spectra for the UCNP1 and UCNP2 materials display five main peaks originating from 200-650 cm-1 along with the two dominant peaks around $245-300 \mathrm{~cm}^{-1}$, which are the characteristic peaks of $\mathrm{NaYF}_{4}$ host lattice. Raman peaks located from the scale of 400 to $700 \mathrm{~cm}^{-1}$ might be denoted for the vibrational frequencies of Na-F. High phonon vibration modes above $1000 \mathrm{~cm}^{-1}$ are weakly present and almost absent in the UCNP1 and UCNP2 [38,39].
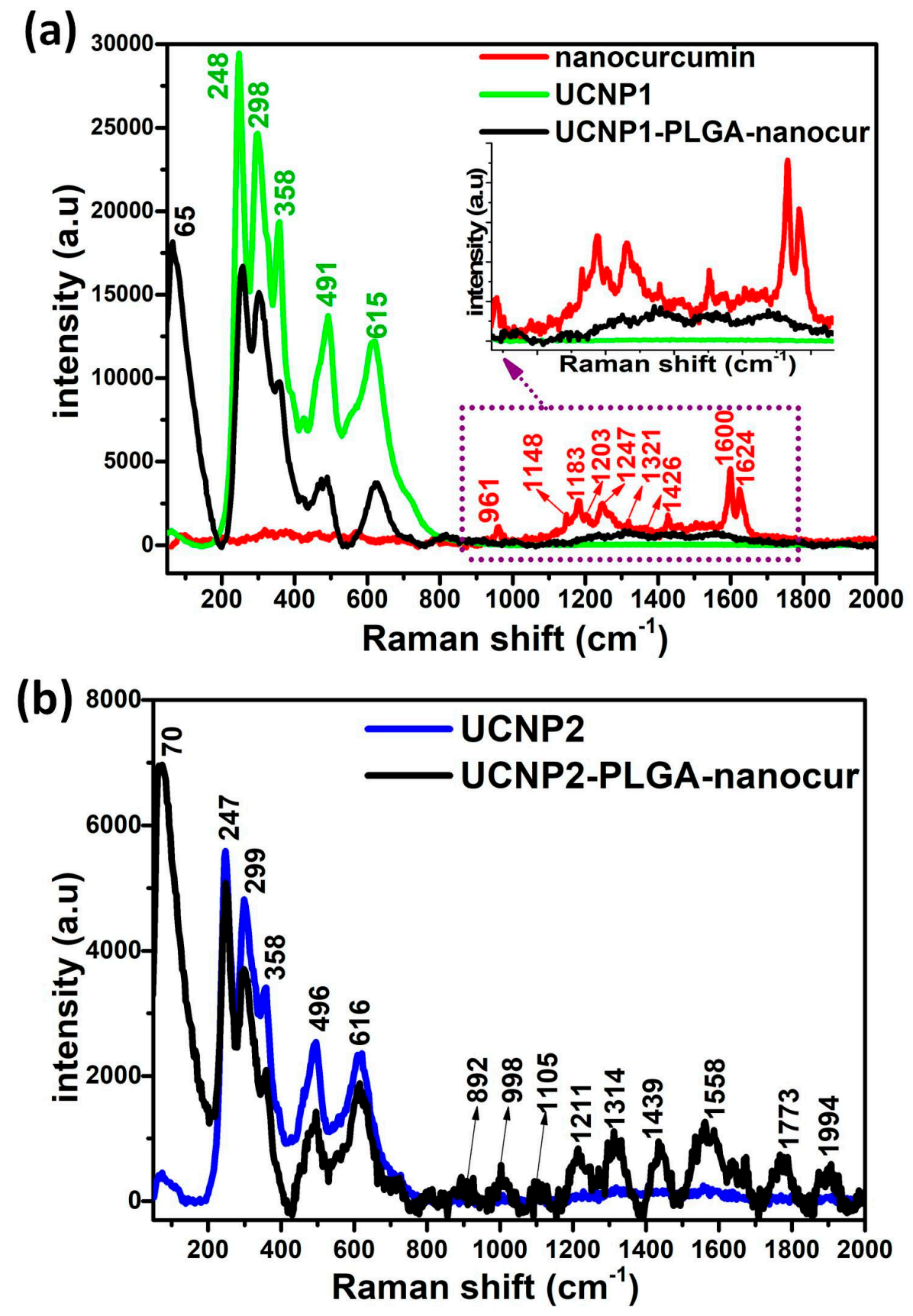

Figure 5. (a) Raman spectra of Nanocurcumin, $\mathrm{NaYF}_{4}: \mathrm{Yb}, \mathrm{Er}$ (UCNP1), UCNP1-PLGA-nanocur

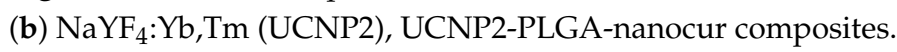

In the case of UCNP1-PLGA-nanocur and UCNP2-PLGA-nanocur, the spectrum displays Raman peaks corresponding to both nanocurcumin and UCNPs, which is an indication of drug loading. No Raman peak is observed above $1000 \mathrm{~cm}^{-1}$ in the UCNP1 and UCNP2. However, the inset of Figure 5a reveals UCNP1-PLGA-nanocur shows Raman modes (1000-1600 $\left.\mathrm{cm}^{-1}\right)$ due to the drug loading of nanocurcumin with the UCNPs. In 
addition, the major functional groups of UCNPs that lies from $200-800 \mathrm{~cm}^{-1}$ remains unaffected by the incorporation of nanocurcumin except a slight decrement in intensity. Similar results are obtained for UCNP2-PLGA-nanocur displayed in Figure $5 b$. The Raman spectral result indicates the nanocurcumin and UCNP nanocarrier is conjugated by the PLGA polymer in the UCNP1-PLGA-nanocur and UCNP2-PLGA-nanocur composites, which could be useful for biomedical applications.

\subsection{NIR to Visible Upconversion Emission Characteristics of $\mathrm{NaYF}_{4}: \mathrm{Yb}, \mathrm{Er} / \mathrm{Tm}$}

Figure 6a-e shows the NIR to visible upconversion emission and NIR to NIR down conversion emission spectra of $\mathrm{NaYF}_{4}: \mathrm{Yb}, \mathrm{Er} / \mathrm{Tm}$ UCNPs, PLGA-UCNPs and nanocurcumin incorporated PLGA-UCNPs. Figure 6a exhibits the upconversion luminescence (UCL) spectra of hexagonal UCNP1, UCNP1-PLGA and UCNP1-PLGA-nanocur under $980 \mathrm{~nm}$ excitation. It exhibits emission at 410,520,540, and $660 \mathrm{~nm}$, which correspond to transitions arising out of ${ }^{2} \mathrm{H}_{9 / 2},{ }^{2} \mathrm{H}_{11 / 2},{ }^{4} \mathrm{~F}_{7 / 2},{ }^{4} \mathrm{~S}_{3 / 2}$ excited levels towards the ${ }^{4} \mathrm{I}_{15 / 2}$ ground level of $\mathrm{Er}^{3+}$ ion $[40,41]$. Hexagonal UCNP1 displays the upconverted intense green and red emission. Xilin Bai et al. demonstrated that strong green emission of UCNPs shows great bioimaging ability and reported the UC red emission is useful for cell therapy [42]. The UCNP1-PLGA provides similar UC emission characteristics, but it shows less intense emission due to the carboxylic functional groups of PLGA [43], which could improve the drug internalization capacity. Nevertheless, the UC emission in PLGA-UCNP could be sufficient enough for bioimaging. A decrement in the UC emission is noticed in the UCNP1-PLGA-nanocur composite due to the presence of organic moiety [44]. However, UC emission of UCNP1-PLGA-nanocur shown in Figure 6a indicate it has considerable spectral intensity of $\sim 2.5 \times 10^{5} \mathrm{cps}$ for green emission and $\sim 3 \times 10^{5} \mathrm{cps}$ for red emission, which may be suitable for cancer imaging and treatment under the action of NIR laser radiation. The upconverted yellow emission was observed from the UCNP1-PLGA-nanocur (inset of Figure 6a) under the influence of $200 \mathrm{mw} 980 \mathrm{~nm}$ NIR diode laser pointer. The UC yellow emission in UCNP1-PLGA-nanocur is for the combination of green and intense red emissions. It implies the nanocurcumin is encapsulated over the UCNPs through PLGA conjugation $[30,45]$ and UC emission in the nanocurcumin drug loaded PLGA-UCNP could play a certain role in cancer bioimaging and therapeutics. Figure $6 \mathrm{~b}$ shows the NIR-to-NIR down conversion fluorescence emission at 1400-1800 nm for the UCNP1 and UCNP1-PLGA nanoparticles.

Figure 6c displays the upconversion luminescence emission spectra of UCNP2, UCNP2PLGA, and UCNP2-PLGA-nanocur composite. All the three samples exhibit weak emission at $480 \mathrm{~nm}$ and intense NIR emission at $800 \mathrm{~nm}$, which are, respectively, assigned to ${ }^{1} \mathrm{G}_{4} \rightarrow{ }^{3} \mathrm{H}_{6}$ and ${ }^{3} \mathrm{H}_{4} \rightarrow{ }^{3} \mathrm{H}_{6}$ transitions of $\mathrm{Tm}^{3+}$ ion [40,41]. The reduction in the peak intensity after PLGA conjugation and nanocurcumin loading are owing to the polymer moiety. The UCNP2-PLGA-nanocur exhibiting blue emission and intense NIR to NIR upconversion emission is a novel result for biological applications. As NIR emission of $\mathrm{Tm}^{3+}$ falls interior in the biological window $700-900 \mathrm{~nm}$, it could lead to low scattering and high penetration in bio tissues.

\subsection{NIR to NIR Downconversion Emission Characteristics}

Figure $6 \mathrm{~b}$ shows the NIR-to-NIR down conversion fluorescence spectra of UCNP1 and UCNP1-PLGA nanoparticles taken in the range of 1400-1800 nm. The emission spectra around $1550 \mathrm{~nm}$ is for the ${ }^{4} \mathrm{I}_{13 / 2} \rightarrow{ }^{4} \mathrm{I}_{15 / 2}$ energy level transition in $\mathrm{Er}^{3+}$ ions. Figure $6 \mathrm{~d}$ shows the NIR-to-NIR down conversion fluorescence spectra of UCNP2, UCNP2-PLGA and UCNP2-PLGA-nanocur from 1100-1300 nm. The infrared emission spectrum centred at $1225 \mathrm{~nm}$ corresponds to ${ }^{3} \mathrm{H}_{5} \rightarrow{ }^{3} \mathrm{H}_{6}$ transition of $\mathrm{Tm}^{3+}$ ion. Figure 6e reveals the downconversion fluorescence spectra of UCNP2, UCNP2-PLGA and UCNP2-PLGA-nanocur from $1600-2000 \mathrm{~nm}$. The infrared emission spectrum centred at $1800 \mathrm{~nm}$ corresponds to ${ }^{3} \mathrm{~F}_{4} \rightarrow{ }^{3} \mathrm{H}_{6}$ transition of $\mathrm{Tm}^{3+}$ ion. 

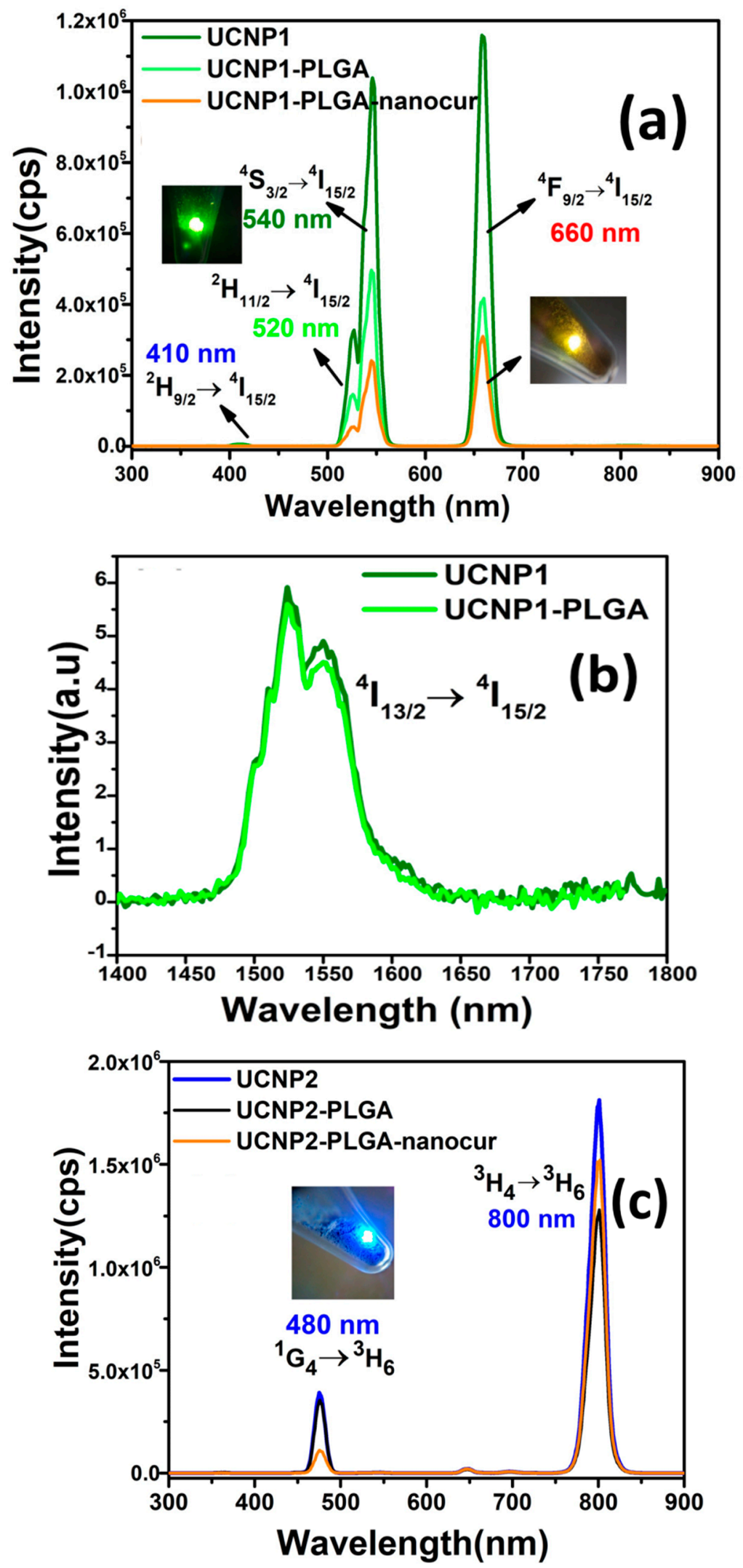

Figure 6. Cont. 

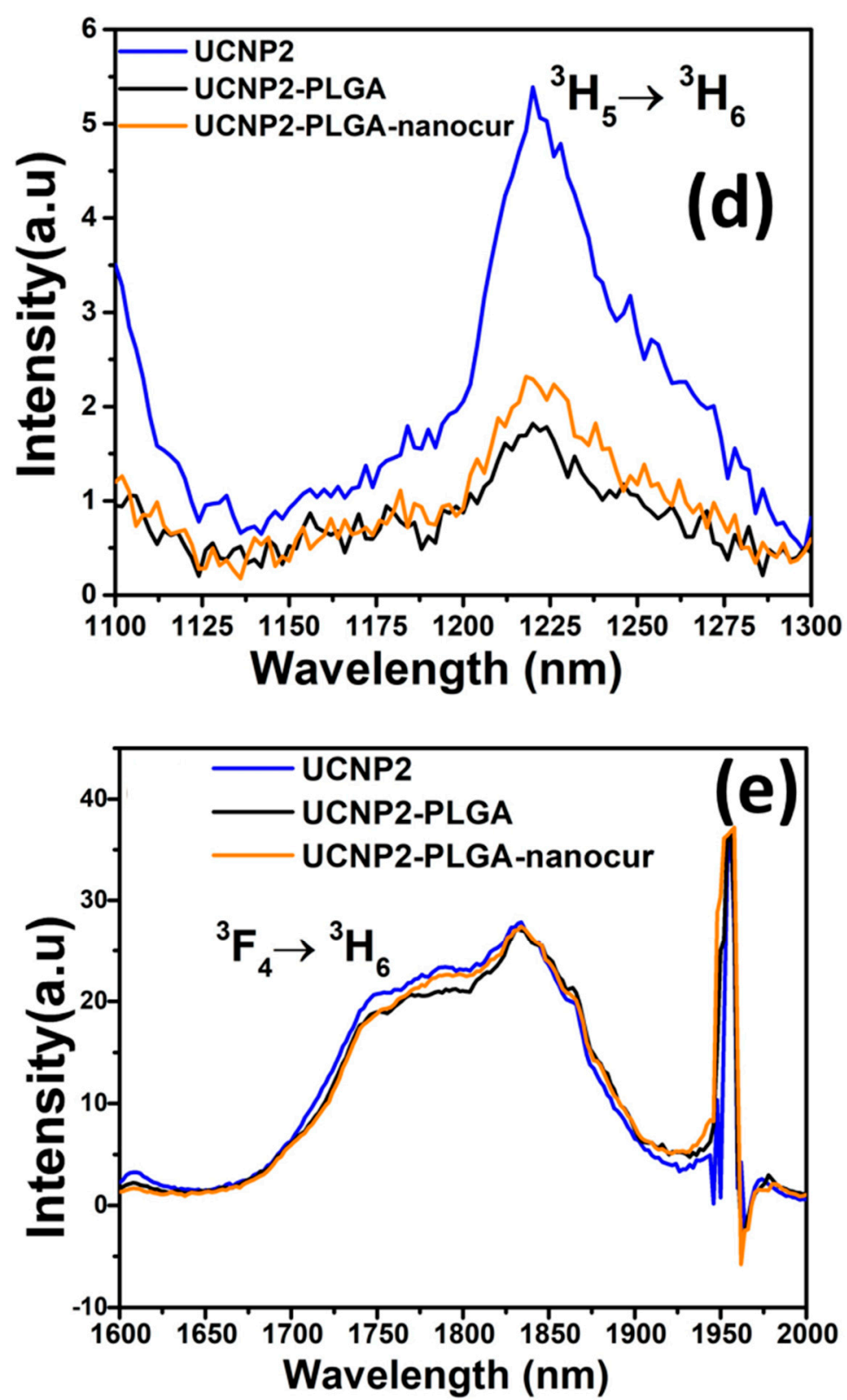

Figure 6. (a) UCL spectra of UCNP1, UCNP1-PLGA and UCNP1-PLGA-nanocur, (b) fluorescence spectra of UCNP1, UCNP1-PLGA, (c) UCL spectra of UCNP2, UCNP2-PLGA and UCNP2-PLGAnanocur (d,e) fluorescence spectra of UCNP2, UCNP2-PLGA and UCNP2-PLGA-nanocur, respectively.

\subsection{FRET Mechanism between UCNPs and Nanocurcumin for PDT}

Based on the literature evidence, the energy transfer mechanism between the UCNP and nanocurcumin for photodynamic therapy (PDT) applications could be explained [46]. It is well known that curcumin is not only used as a natural drug to treat various diseases, but it also used as a photosensitizer for PDT [47]. The synthesized nanocurcumin has optical absorption in the UV (270 and $350 \mathrm{~nm}$ ) and visible ( 400 to 450) spectral range (Figure S1, discussed in the supplementary section). By exploiting the broad optical absorption behaviour of curcumin, one can use it as photosensitizer molecule for PDT by blue light activation [48-50] by blue LED or laser sources. However, weak point is that it does not have NIR absorption capability, and hence it is not suitable for NIR light induced PDT applications. When nanocurcumin is functionalized with $\mathrm{NaYF}_{4}: \mathrm{Yb}, \mathrm{Tm}$ nanoparticle, under the influence of $980 \mathrm{~nm}$ diode laser excitation (Figure 6c), the curcumin can be activated by the upconverted light at 450 to $500 \mathrm{~nm}$ by resonant energy transfer from the Thulium 
donor ion of UCNPs to the acceptor nanocurcumin photosensitizer. It has been reported that the Förster resonant energy transfer between the UCNP and curcumin molecule [51] could provide dual activation in the UCNP-nanocurcumin nanocomplex, generate reactive oxygen species (ROS) and kill the cancer cells. Therefore, UCNP-Nanocurcumin could be served as a potential nanocomplex for PDT compared to the bare nanocurcumin [52].

\subsection{In Vitro Cytotoxicity Studies}

The in vitro cytotoxicity of the bare drug-free UCNPs and nanocur-loaded UCNPs was evaluated using rat glioma C6 cells (Figure 7). We used glioma cells since the potential of curcumin in the glioma and glioblastoma treatment has been demonstrated earlier $[53,54]$. The blank $\mathrm{NaYF}_{4}: \mathrm{Yb}$,Er and $\mathrm{NaYF}_{4}: \mathrm{Yb}, \mathrm{Tm}$ nanoparticles demonstrated dose-dependent cytotoxicity with slight cell growth inhibition at $0.05 \mathrm{mg} / \mathrm{mL}$ and higher; however, even at $0.8 \mathrm{mg} / \mathrm{mL}$ cell viability was above $50 \%$ that confirmed the suitability of developed UCNPs for biomedical applications. The $\mathrm{NaYF}_{4}: \mathrm{Yb}$,Er-PLGA-nanocur and $\mathrm{NaYF}_{4}: \mathrm{Yb}$,Tm-PLGAnanocur found to more toxic to cells, and cell viability at $0.8 \mathrm{mg} / \mathrm{mL}$ was $24 \pm 4 \%(p<0.05)$ and $19 \pm 6 \%(p<0.05)$, respectively. It should be noted, that at lower concentrations the toxicity of nanocur-loaded and blank UCNPs was similar that could be explained with prolong drug release and comparatively low nanocurcumin toxicity. The curcumin loaded porous silica tested in HT-29 and NCM460 cells. The cell viability was reported to be $50 \%$ at a low concentration of $50 \mu \mathrm{g} / \mathrm{mL}$ or $0.05 \mathrm{mg} / \mathrm{mL}$ [55], and at this concentration the present UCNP-PLGA-nanocurcumin showed more than $60 \%$ cell viability. The nanocurcumin loaded UCNP-PLGA nanocomplexes showed moderate cytotoxicity (Figure 7) against the rat glioma C6 cells compared to drug free UCNPs. It may give good cell viability with other cancer cell lines, but it has to be investigated in detail. By carefully controlling the particle size and solubility of nanocurcumin, its physico-chemical properties could be improved to make it useful for anti-cancer application. In addition to the in vitro cell viability, in order to utilize the UCNP-Nanocurcumin complexes for PDT applications, it is important to examine the phototoxicity of UCNP under illumination of NIR light activation. It is planned to investigate the phototoxicity of present UCNP-Nanocurcumin complexes and present as an extension of the current work. The Russian researchers Minorova et al. and Khayduko et al. investigated the phototoxicity effect of specially designed $\mathrm{NaYF}_{4}: \mathrm{YbEr}$ and $\mathrm{NaYF}_{4}: \mathrm{YbTm}$ nanoparticles under the $975 \mathrm{~nm}$ NIR diode laser illumination and demonstrated a new approach on PDT by the UCNP mediated UV and UV-blue light excitation mechanism to generate ROS for killing the cancer cells [56,57].

\subsection{Tumor Spheroids Model}

The toxicity of UCNPs was also evaluated in tumour spheroids model. Tumour spheroids are three-dimensional cell aggregates that mimic some features of tumours in vivo, including cell-cell and cell-matrix interactions, gradients, and higher drug resistance, so tumour spheroids could be discussed as an advanced in vitro model of in vivo tumours $[58,59]$.

Indeed, $\mathrm{C} 6$ cells in spheroids were more resistant to treatment with $\mathrm{NaYF}_{4}: \mathrm{Yb}, \mathrm{Er}$ PLGA-nanocur and $\mathrm{NaYF}_{4}: \mathrm{Yb}$,Tm-PLGA-nanocur in comparison to monolayer culture with viability of $70 \pm 6 \%$ and $74 \pm 3 \%$ at $0.8 \mathrm{mg} / \mathrm{mL}$, respectively (Figure 8 ). The disruption of the outer cell layer of spheroids within $48 \mathrm{~h}$ treatment in comparison to control intact spheroid (A) is demonstrated on (B, C) in Figure 9. By using the confocal fluorescent microscopy, the cell viability in glioma C6 spheroids was visualized with calcein AM (alive cells) and propidium iodide (dead cells) staining (Figure 10). Propidium iodide staining (in red) of cell nucleuses confirms partial cell death in spheroids under $\mathrm{NaYF}_{4}$ :Yb,Er-PLGAnanocur (A) and $\mathrm{NaYF}_{4}: \mathrm{Yb}$,Tm-PLGA-nanocur (B) treatment. 

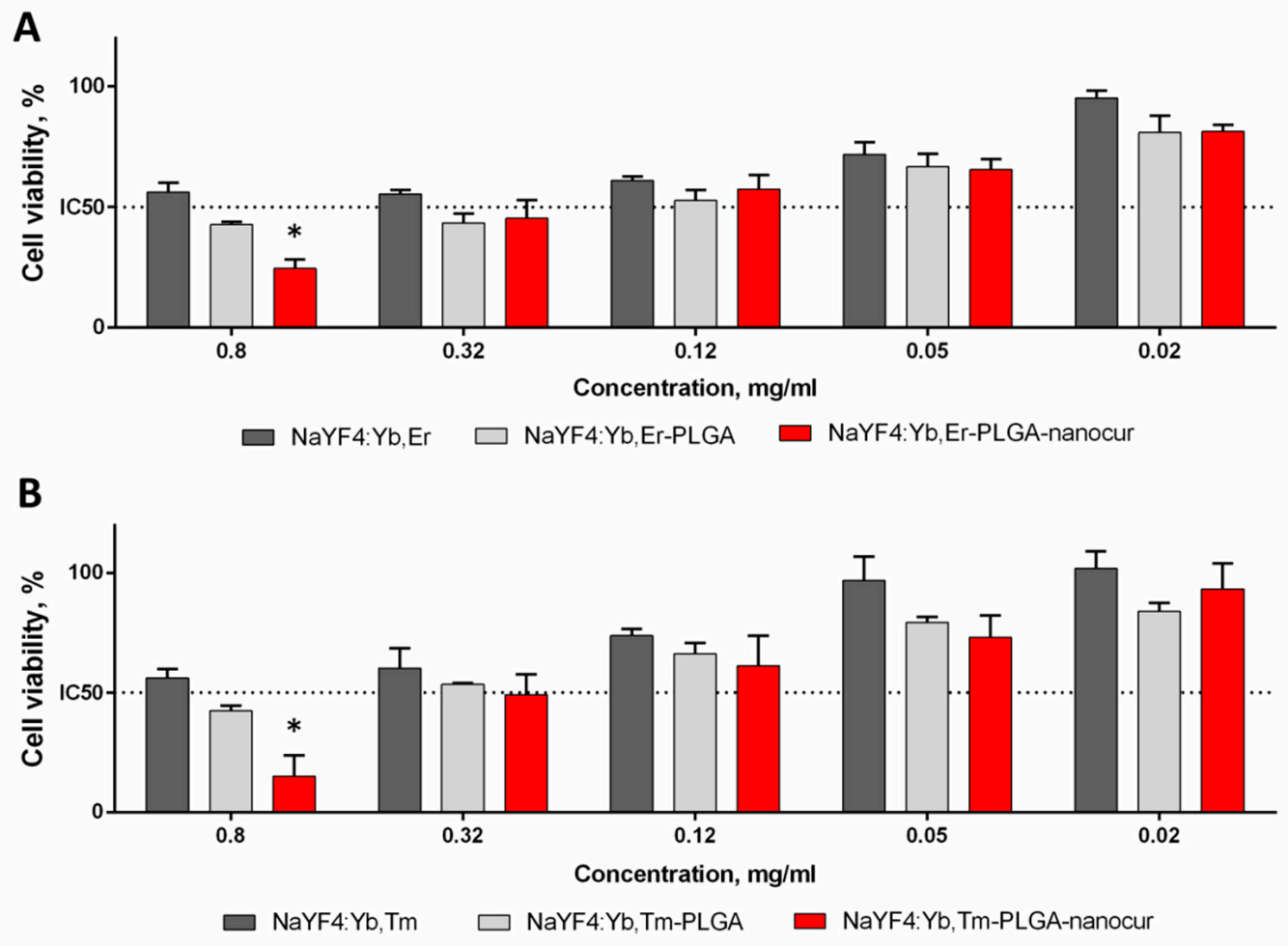

Figure 7. Viability of rat glioma $\mathrm{C} 6$ cells after $48 \mathrm{~h}$ of incubation with $\mathrm{NaYF}_{4}: \mathrm{Yb}$, Er-based (A) and $\mathrm{NaYF}_{4}: \mathrm{Yb}$,Tm-based (B) nanoparticles. MTT assay, the viability of intact cells was taken as $100 \%$. ${ }^{*} p<0.05$ in comparison to blank nanoparticles in Mann-Whitney U test (non-parametric, two-tailed).

\section{C6 spheroids, $48 \mathrm{~h}$}

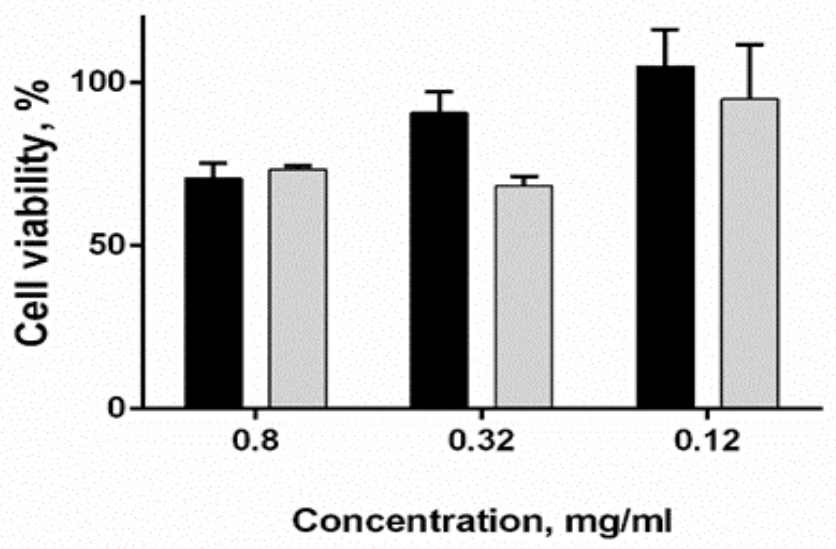

Er/nanocur/PLGA $\square$ Tm/nanocur/PLGA

Figure 8. Viability of $\mathrm{C} 6$ cells in spheroids after $48 \mathrm{~h}$ of incubation with $\mathrm{NaYF}_{4}: \mathrm{Yb}, \mathrm{Er}-\mathrm{PLGA}$-nanocur and $\mathrm{NaYF}_{4}: \mathrm{Yb}$,Tm-PLGA-nanocur. MTS assay, the viability of intact cells was taken as $100 \%$. 


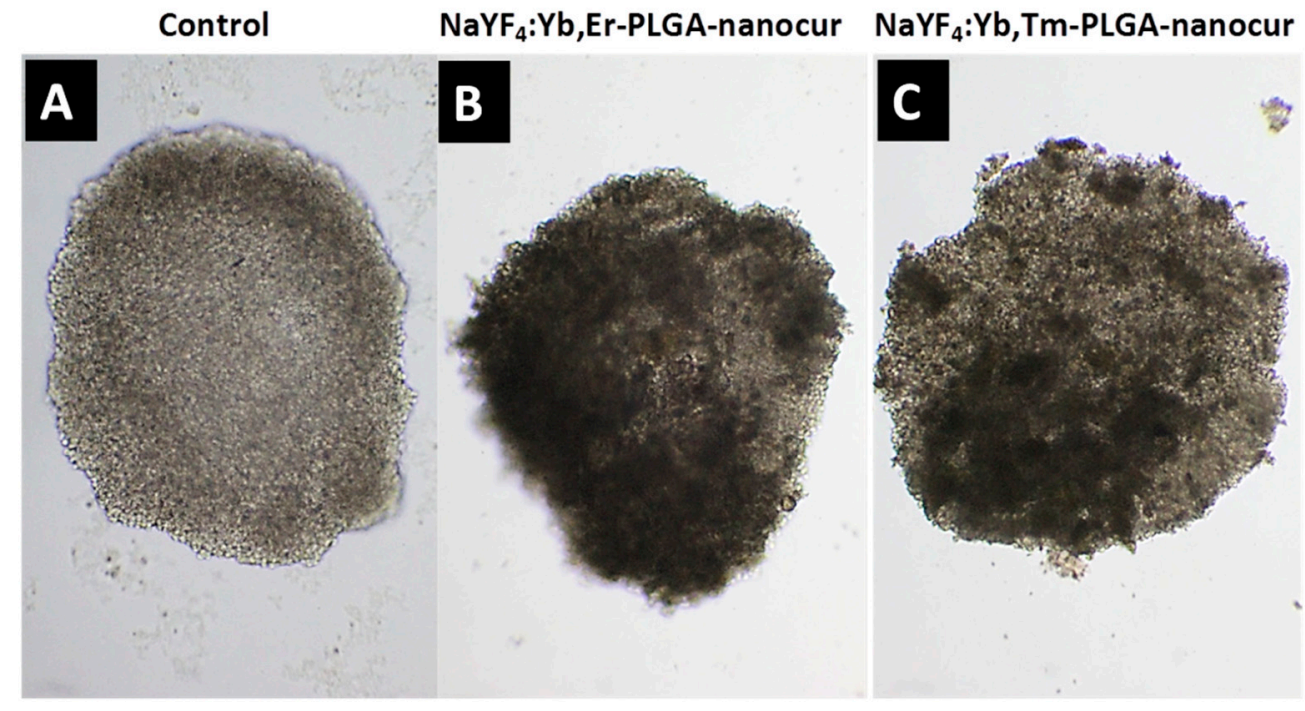

Figure 9. Micrographs of rat glioma C6 spheroids incubated with $0.4 \mathrm{mg} / \mathrm{mL}$ UCNPs for $48 \mathrm{~h}$, lens $10 \times$. Spheroids represent the 3D cell culture model similar to tumors in vivo. The outer cell layer is damaged in case of treated spheroids $(\mathbf{B}, \mathbf{C})$ in comparison to the control intact spheroid (A).

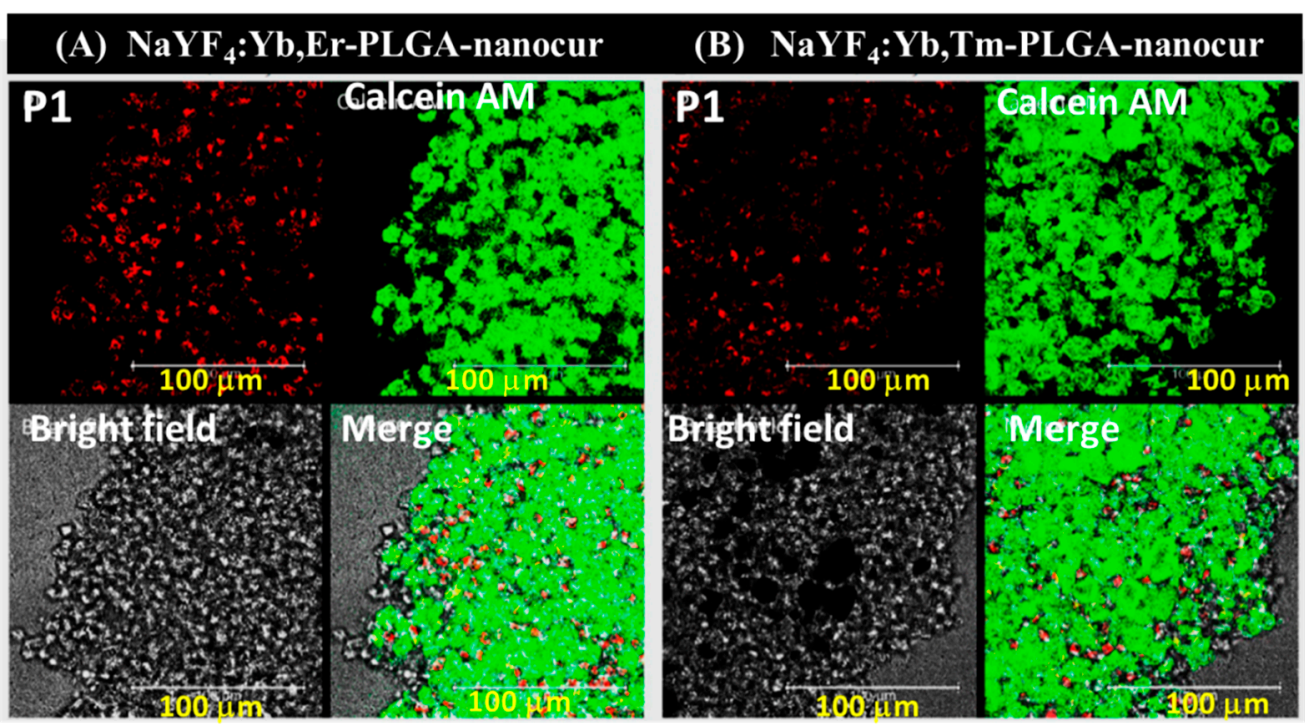

Figure 10. Confocal fluorescent microscopy micrographs of rat glioma C6 spheroids incubated with $0.4 \mathrm{mg} / \mathrm{mL}$ UCNPs for $48 \mathrm{~h}, \mathrm{NaYF}_{4}: \mathrm{YbEr}$ PLGA nanocur $(\mathbf{A})$ and $\mathrm{NaYF}_{4}$ :YbTm PLGA nanocur (B) The spheroids were stained with propidium iodide (dead cells, in red) and calcein AM (alive cells, in green), scale bar is $100 \mu \mathrm{m}$.

\subsection{In Vitro Distribution of UCNPs in Rat Glioma Cells and Imaging Studies}

We evaluated the in vitro distribution of UCNPs in rat C6 Glioma cells using antiStokes photoluminescence microscopy and confocal fluorescence microscopy. It was demonstrated that UCNPs were able to accumulate in cells within $1 \mathrm{~h}$, and this could be visualized both in anti-Stokes photoluminescence (Figure 11) and fluorescence (Figure 12) mode. Both approaches provide similar UCNPs distribution in cells, but anti-Stokes photoluminescence provides higher signal-to-noise ratio due to the absence of background signal. It should be noted that PLGA-coated and PLGA-nanocur-coated UCNPs better accumulated in cells that could be explained with cell-particles interactions in case of PLGA modification (Figure 11). This correlates with MTT assay data that were discussed above. Since the penetration into solid tumours is one of the limitations for nano-based 
formulations, we additionally evaluated the accumulation of UCNPs in tumour spheroids. We demonstrated the accumulation of UCNPs in spheroids after $48 \mathrm{~h}$ incubation, but not after $2 \mathrm{~h}$ (Figure 13). The penetration depth is at least $100 \mu \mathrm{m}$.

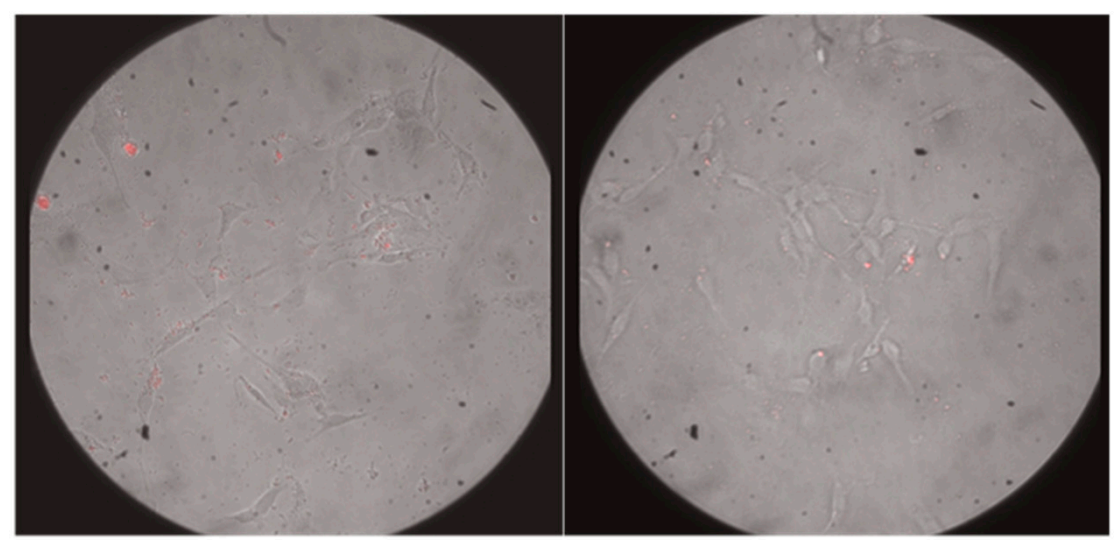

$\mathrm{NaYF}_{4}: \mathrm{Yb}, \mathrm{Er}-\mathrm{PLGA}$

$\mathrm{NaYF}_{4}: \mathrm{Yb}, \mathrm{Tm}-\mathrm{PLGA}$

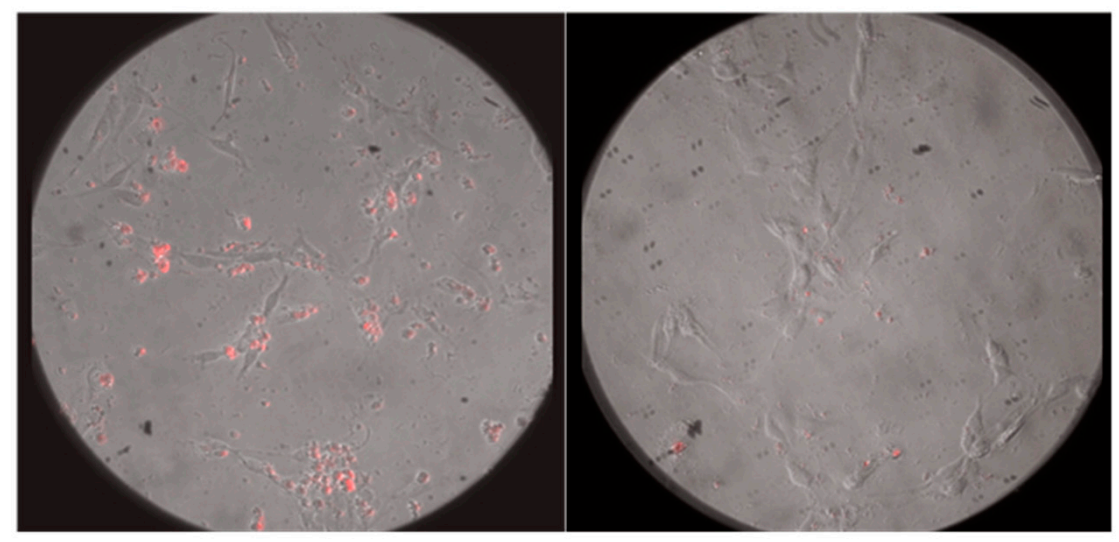

$\mathrm{NaYF}_{4}: \mathrm{Yb}, \mathrm{Er}-\mathrm{PLGA}$-nanocur $\mathrm{NaYF}_{4}: \mathrm{Yb}, \mathrm{Tm}$-PLGA-nanocur

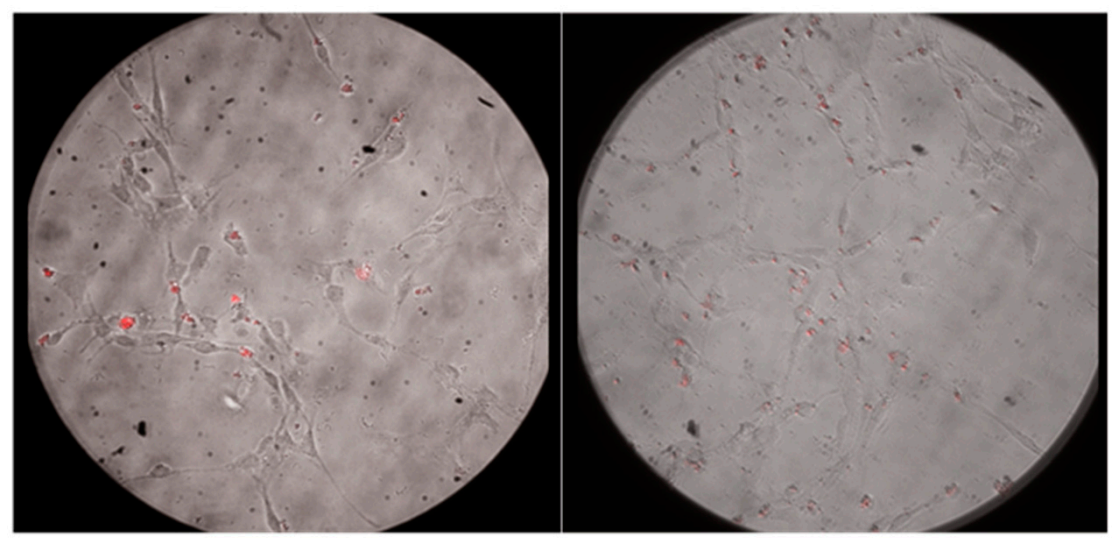

Figure 11. Micrographs of rat C6 glioma cells in an upconverting luminescence microscope: UCNPs concentration $0.05 \mathrm{mg} / \mathrm{mL}, 30 \mathrm{~min}$ of incubation. The upconversion signal is in red. Lens $10 \times$. 


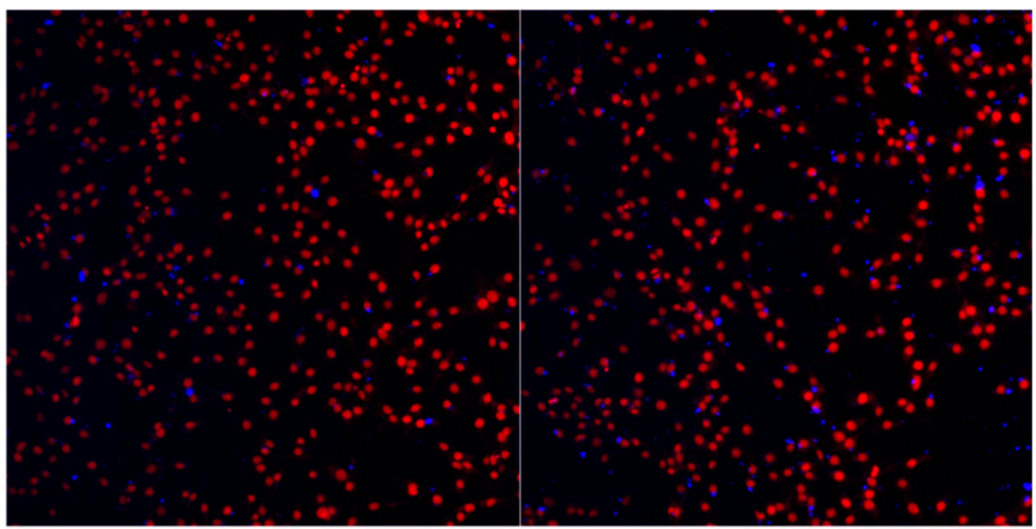

Figure 12. Micrographs of rat C6 glioma cells under a fluorescence microscope: UCNPs concentration $0.05 \mathrm{mg} / \mathrm{mL}, 30 \mathrm{~min}$ of incubation. Cell nuclei are marked in red, the fluorescence of nanocurcumin is marked in blue. Excitation of nanocurcumin was induced by irradiation at $488 \mathrm{~nm}$. Lens $10 \times$.
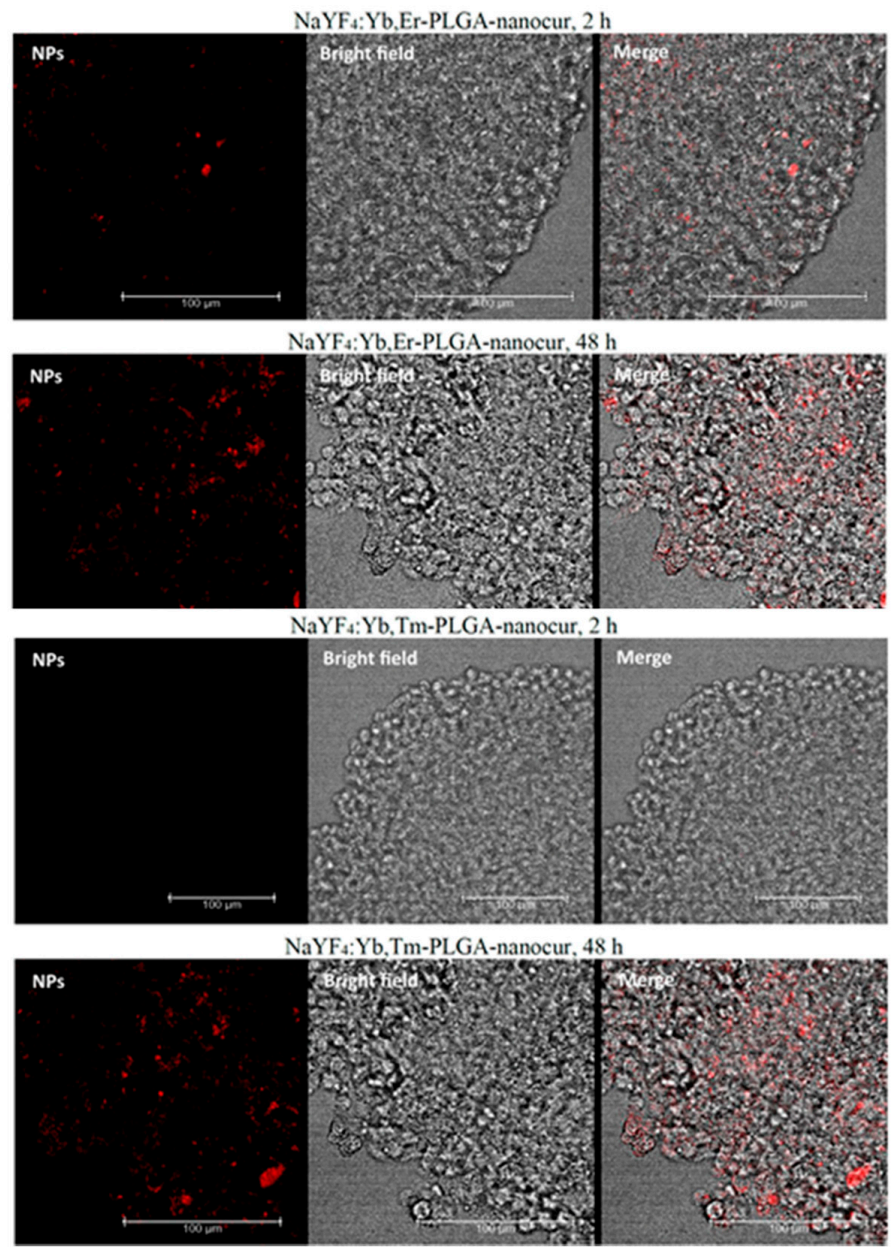

Figure 13. Micrographs of rat glioma C6 spheroids, $0.4 \mathrm{mg} / \mathrm{mL}$ UCNPs, $2 \mathrm{~h}$ and $48 \mathrm{~h}$ incubation, confocal fluorescent microscopy. The fluorescence of nanocurcumin is indicated in red, $488 \mathrm{~nm}$ excitation. Scale bar is $100 \mu \mathrm{m}$.

\subsection{In Vivo Distribution of UCNPs and Small Animal Imaging Studies}

We evaluated the biodistribution of UCNPs in vivo using DVS-02 small animals imaging system. We found that UCNPs accumulated in the liver, lungs, intestines, and 
spleen in $4 \mathrm{~h}$ after administration (Figures 14 and 15), which corresponds to the common biodistribution pattern of nanoparticles after systemic administration. A significant amount of UCNPs in the intestine confirms their ability to be excreted from the body. Indeed, the UCNPs signal decreased significantly after $24 \mathrm{~h}$ post-injection. It should be noted that $\mathrm{NaYF}_{4}: \mathrm{Yb}$,Tm showed a brighter luminescent signal compared to $\mathrm{NaYF}_{4}: \mathrm{Yb}$,Er, which can be explained by a higher quantum yield. At the same time, a slight decrease of the signal was found in the $\mathrm{NaYF}_{4}: \mathrm{Yb}$,Tm-PLGA-nanocur sample in comparison with $\mathrm{NaYF}_{4}: \mathrm{Yb}$,Tm-PLGA (Figure 15). Lewis lung cancer was used as a mouse tumour model. We demonstrated that in the case of peritumoral administration, UCNPs were detected in the tumour site for a long time (at least $24 \mathrm{~h}$ ), which indicates the ability of UCNPs to persist in the tumour tissue.

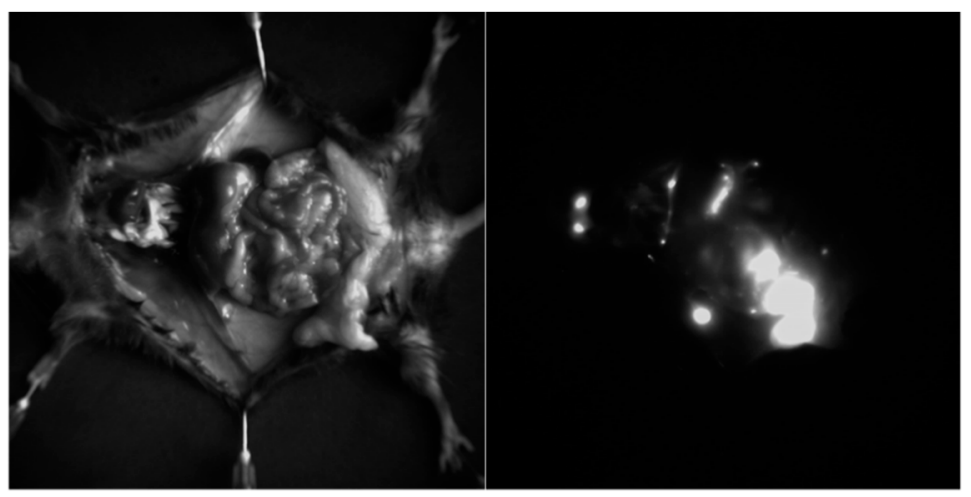

Figure 14. Bright-field image of the mouse organocomplex (left) and epiluminescent image of the mouse organocomplex marked with $\mathrm{NaYF}_{4}: \mathrm{Yb}$,Tm -PLGA-nanocur (right), intravenous injection of $0.75 \mathrm{mg}$ UCNPs, $4 \mathrm{~h}$ after injection.

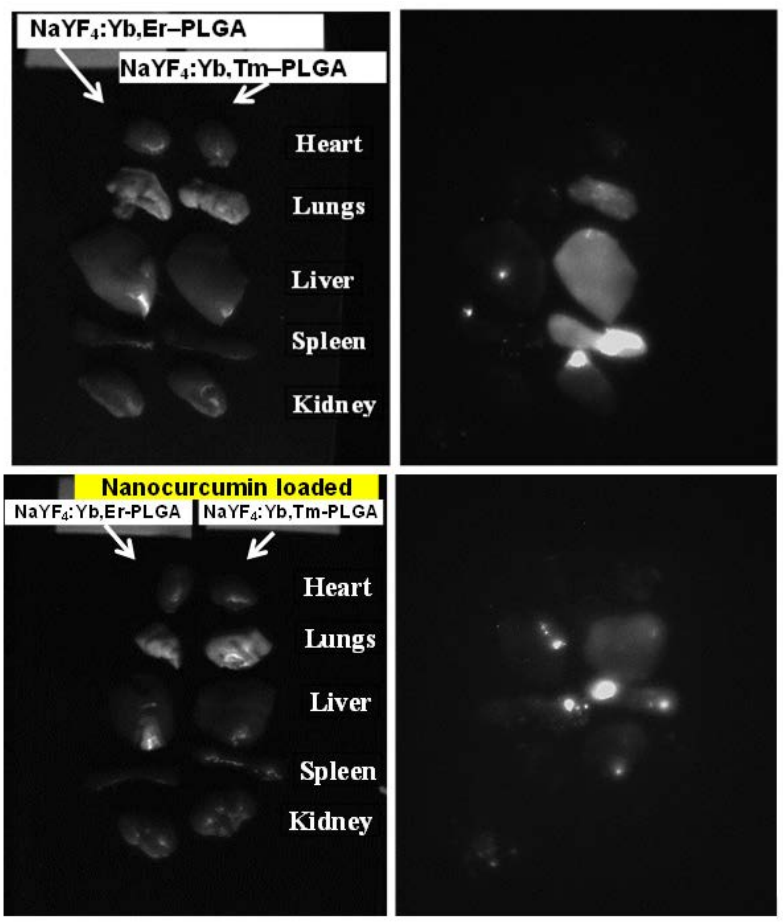

Figure 15. Bright-field image of the ex vivo organs (left) and epiluminescent image of the mouse organocomplex (right). Intravenous injection of $0.75 \mathrm{mg}$ UCNPs, $4 \mathrm{~h}$ after injection. (Upper row- $\mathrm{NaYF}_{4}: \mathrm{Yb}$,Er-PLGA and $\mathrm{NaYF}_{4}: \mathrm{Yb}$,Tm-PLGA, lower row-NaYF $4: \mathrm{Yb}$,Er-PLGA-nanocur and $\mathrm{NaYF}_{4}: \mathrm{Yb}, \mathrm{Tm}-\mathrm{PLGA}$-nanocur). 


\section{Conclusions}

In summary, we demonstrated assembling nanocurcumin with UCNPs via introducing an intermediate stage of UCNP coating with PLGA endowed the as-synthesised nanocomplexes optical contrast in the near-infrared transparency window. $\mathrm{NaYF}_{4}: \mathrm{Yb}, \mathrm{Er}-$ PLGA-nanocurcumin and $\mathrm{NaYF}_{4}: \mathrm{Yb}, \mathrm{Tm}$-PLGA-nanocurmin, respectively, exhibited upconversion emission at 520,540,660 $\mathrm{nm}$ and 480 and $800 \mathrm{~nm}$ spectral bands at $980 \mathrm{~nm}$ diode laser excitation. PLGA functionalized $\mathrm{NaYF}_{4}: \mathrm{Yb}, \mathrm{Er} / \mathrm{Tm}$ and nanocurcumin drug loaded PLGA-UCNPs showed $60-80 \%$ cell viability at $0.12-0.02 \mathrm{mg} / \mathrm{mL}$ in the rat C6 glioma cell medium. In vitro distribution of UCNPs in rat C6 glioma cells and imaging studies demonstrated the accumulation of UCNPs in the cancer spheroids. Peritumoral administration of UCNP-PLGA-nanocur to Lewis lung cancer bearing animal models rendered the tumour lesion optical contrast, which persisted for at least $24 \mathrm{~h}$. This enabled in vivo and ex vivo study of UCNP-PLGA-nanocur biodistribution in organs, and showed accumulation in the liver and lungs. Our studies demonstrated promise of nanocurcumin-loaded upconversion nanoparticles for theranostics applications.

Supplementary Materials: The following are available online at https:/ /www.mdpi.com/article/10 .3390/nano11092234/s1, Figure S1: (a) UV-VIS absorption spectra (b) photoluminescence spectra of raw curcumin and nanocurcumin; Figure S2: Thermal analysis of nanocurcumin, (a) DTA and (b) TGA profile; Figure S3(a): EDAX survey spectrum of NaYF4:Yb,Er-PLGA-Nanocurcumin complex; Figure S3(b): EDAX spectrum in the range 0 to $3 \mathrm{keV}$ shows strong peaks for the elements $\mathrm{F}, \mathrm{Y}$, and $\mathrm{Na}$ ion and less intense peaks from 1.4 and 2 kev related to M-shell X-ray emission energy lines for dopant $\mathrm{Yb}$ and Er ions. The organic species C, N, O are from PLGA polymer and curcumin drug,; Figure S3(c): EDAX spectrum in the range 6 to $10 \mathrm{keV}$ shows very weak peaks for $\mathrm{Yb}$ and Er due to their L-shell $\mathrm{X}$-ray emission energy lines; Figure S4: EDAX elemental mapping of $\mathrm{Na}, \mathrm{Y}, \mathrm{F}, \mathrm{C}, \mathrm{O}, \mathrm{Er}$, $\mathrm{Yb}$ elements in the NaYF4:Yb,Er-PLGA-Nanocur complex; Table S1: Zeta potential values of UCNP-Nanocurcumin complexes; Figure S5: Zeta potential profiles of the nanocurcumin, UCNP1 (NaYF4:Yb,Er), UCNP1PLGA-nanocurcumin, UCNP2 (NaYF4:Yb,Tm) and UCNP2-PLGA-nanocurcumin complex (taken in aqueous solution at $\mathrm{pH}$ 7).

Author Contributions: S.J. and R.A.A. designed and conceptualized the project, generated the research grant, and supervised the India-Russia bilateral research project. A.L. and M.J. are involved in the sample synthesis and materials characterizations. A.G. and D.K.S. performed the upconversion emission measurements. Russian team members R.A.A., N.V.S., P.A.D., A.N.G., K.B.L., D.A.K., E.V.K. and S.V.G. have contributed to the bio-investigations such as in-vitro cytotoxicity, bio imaging, in-vivo small animal studies, validation, and visualization. A.L., S.J. and R.A.A. involved in the first write-up of the manuscript. S.J. and R.A.A. have analysed the results, modified and revised the manuscript in the present form. All authors have read and agreed to the published version of the manuscript.

Funding: This project grant is supported by Department of Science and Technology (DST, India) of the Government of India (INT/RUS/RFBR/P-333 Dated 2 January 2019) and Russian Foundation for Basic Research (No.18-54-45034 IND) in the section "Creation of a Theranostic Nanostructure," the Ministry of Science and Higher Education under the State assignment of the Federal Research Center Crystallography and Photonics of the Russian Academy of Sciences in the section "Anti-Stokes Microscopy," and the Russian Foundation for Basic Research (Project no. 18-29-01021) in the section "Testing on Glioblastoma Cells".

Acknowledgments: The authors S.J. and R.A.A. thank the DST-India and the Russian Foundation for Basic Research (RFBR) for the award of the India-Russian Project (INT/RUS/RFBR/P-333 Dated 2 January 2019). The Indian principal investigator S.J. thanks Andrei Zvyagin (I M Sechenov First Moscow State Medical University, Russia) for his dedicated involvement as Principle investigator in the DST-RFBR supported bilateral project. A.L. thanks the DST-India for the Junior Research Fellowship position that enabled her to perform upconversion materials synthesis and characterization for her Ph.D. thesis research. A.G acknowledges the National Science Foundation Partnerships for Research and Education in Materials (NSF-PREM) grant NO-DMR-0934218.

Conflicts of Interest: The authors declare no conflict of interest. This manuscript does not contain any bio studies on human participants by any of the authors. 


\section{References}

1. Yallapu, M.M.; Nagesh, P.K.B.; Jaggi, M.; Chauhan, S.C. Therapeutic Applications of Curcumin Nanoformulations. AAPS J. 2015, 17, 1341-1356. [CrossRef]

2. Kızlbey, K. Optimization of Rutin-Loaded PLGA Nanoparticles Synthesized by Single-Emulsion Solvent Evaporation Method. ACS Omega 2019, 4, 555-562. [CrossRef]

3. Li, Z.; Zhang, Y.; La, H.; Zhu, R.; El-Banna, G.; Wei, Y.; Han, G. Upconverting NIR Photons for Bioimaging. Nanomaterials 2015, 5, 2148-2168. [CrossRef] [PubMed]

4. Janjua, R.A.; Gao, C.; Dai, R.; Sui, Z.; Raja, M.A.A.; Wang, Z.; Zhen, X.; Zhang, Z.; Zheng, X. Na ${ }^{+}$-Driven Nucleation of $\mathrm{NaYF}_{4}: \mathrm{Yb}$,Er Nanocrystals and Effect of Temperature on Their Structural Transformations and Luminescent Properties. J. Phys. Chem. C 2018, 122, 23242-23250. [CrossRef]

5. Mancic, L.; Djukić-Vuković, A.; Dinić, I.; Nikolic, M.; Rabasovic, M.; Krmpot, A.J.; Costa, A.M.; Trisic, D.; Lazarevic, M.; Mojovic, L.; et al. NIR photo-driven upconversion in $\mathrm{NaYF}_{4}: \mathrm{Yb}, \mathrm{Er} / \mathrm{PLGA}$ particles for in vitro bioimaging of cancer cells. Mater. Sci. Eng. C 2018, 91, 597-605. [CrossRef]

6. Carvalho, D.D.M.; Takeuchi, K.P.; Geraldine, R.M.; De Moura, C.J.; Torres, M.C.L. Production, solubility and antioxidant activity of curcumin nanosuspension. Food Sci. Technol. 2015, 35, 115-119. [CrossRef]

7. Gutierrez, J.K.T.; Zanatta, G.C.; Ortega, A.L.M.; Balastegui, M.I.C.; Sanitá, P.V.; Pavarina, A.C.; Barbugli, P.; Mima, E.G.D.O. Encapsulation of curcumin in polymeric nanoparticles for antimicrobial Photodynamic Therapy. PLoS ONE 2017, 12, e0187418. [CrossRef]

8. Ghosh, M.; Singh, A.T.; Xu, W.; Sulchek, T.; Gordon, L.I.; Ryan, R.O. Curcumin nanodisks: Formulation and characterization. Nanomed. Nanotechnol. Biol. Med. 2011, 7, 162-167. [CrossRef] [PubMed]

9. Subramani, P.A.; Panati, K.; Lebaka, V.R.; Reddy, D.D.; Narala, V. Nanostructures for Curcumin Delivery: Possibilities and Challenges. In Nano-and Microscale Drug Delivery Systems; Elsevier: Amsterdam, The Netherlands, 2017; pp. $393-418$.

10. Shehzad, A.; Ul-Islam, M.; Wahid, F.; Lee, Y.S. Multifunctional Polymeric Nanocurcumin for Cancer Therapy. J. Nanosci. Nanotechnol. 2014, 14, 803-814. [CrossRef] [PubMed]

11. Pandit, R.S.; Gaikwad, S.C.; Agarkar, G.A.; Gade, A.K.; Rai, M. Curcumin nanoparticles: Physico-chemical fabrication and its in vitro efficacy against human pathogens. 3 Biotech 2015, 5, 991-997. [CrossRef]

12. Azami, S.J.; Teimouri, A.; Keshavarz, H.; Amani, A.; Esmaeili, F.; Hasanpour, H.; Elikaee, S.; Salehiniya, H.; Shojaee, S. Curcumin nanoemulsion as a novel chemical for the treatment of acute and chronic toxoplasmosis in mice. Int. J. Nanomed. 2018, 13, 7363-7374. [CrossRef]

13. Nata, I.F.; Chen, K.-J.; Lee, C.-K. Facile microencapsulation of curcumin in acetylated starch microparticles. J. Microencapsul. 2013, 31, 344-349. [CrossRef]

14. Singh, P.K.; Wani, K.; Kaul-Ghanekar, R.; Prabhune, A.; Ogale, S. From micron to nano-curcumin by sophorolipid co-processing: Highly enhanced bioavailability, fluorescence, and anti-cancer efficacy. RSC Adv. 2014, 4, 60334-60341. [CrossRef]

15. Hu, L.; Jia, Y.; Niu, F.; Jia, Z.; Yang, X.; Jiao, K. Preparation and enhancement of oral bioavailability of curcumin using microemulsions vehicle. J. Agric. Food Chem. 2012, 60, 7137-7141. [CrossRef]

16. Bhawana, B.R.; Buttar, H.S.; Jain, V.; Jain, N. Curcumin nanoparticles: Preparation, characterization, and antimicrobial study. J. Agric. Food Chem. 2011, 59, 2056-2061. [CrossRef]

17. Raghavendra, G.M.; Jayaramudu, T.; Varaprasad, K.; Ramesh, S.; Raju, K.M. Microbial resistant nanocurcumin-gelatin-cellulose fibers for advanced medical applications. RSC Adv. 2014, 4, 3494-3501. [CrossRef]

18. Tahmasebi Birgani, M.; Erfani, V.; Babaei, E.; Najafi, F.; Zamani, M.; Shariati, M.; Nazem, S.; Farhangi, B.; Motahari, P.; Sadeghizaded, M. Dendrosomal nano-curcumin; The novel formulation to improve the anticancer properties of curcumin. Prog. Biol. Sci. 2015, 5, 143-158.

19. Misra, R.; Sahoo, S.K. Correction to Coformulation of Doxorubicin and Curcumin in Poly-(d,l-lactide-co-glycolide) Nanoparticles Suppresses the Development of Multidrug Resistance in K562 Cells. Mol. Pharm. 2013, 10, 4746. [CrossRef]

20. Basniwal, R.K.; Khosla, R.; Jain, N. Improving the anticancer activity of curcumin using nanocurcumin dispersion in water. Nutr. Cancer 2014, 66, 1015-1022. [CrossRef]

21. Wu, X.; Xu, J.; Huang, X.; Wen, C. Self-microemulsifying drug delivery system improves curcumin dissolution and bioavailability. Drug Dev. Ind. Pharm. 2011, 37, 15-23. [CrossRef]

22. Li, Z.; Zhang, Y. An efficient and user-friendly method for the synthesis of hexagonal-phase NaYF 4 :Yb, Er/Tm nanocrystals with controllable shape and upconversion fluorescence. Nanotechnology 2008, 19, 345606. [CrossRef]

23. Gunaseelan, M.; Yamini, S.; Kumar, G.; Senthilselvan, J. Highly efficient upconversion luminescence in hexagonal $\mathrm{NaYF}_{4}: \mathrm{Yb}^{3+}$, $\mathrm{Er}^{3+}$ nanocrystals synthesized by a novel reverse microemulsion method. Opt. Mater. 2017, 75, 174-186. [CrossRef]

24. Jin, H.; Pi, J.; Zhao, Y.; Jiang, J.; Li, T.; Zeng, X.; Yang, P.; Evans, C.E.; Cai, J. EGFR-targeting PLGA-PEG nanoparticles as a curcumin delivery system for breast cancer therapy. Nanoscale 2017, 9, 16365-16374. [CrossRef]

25. Khalil, N.M.; Nascimento, T.C.F.D.; Casa, D.M.; Dalmolin, L.F.; de Mattos, A.C.; Hoss, I.; Romano, M.A.; Mainardes, R. Pharmacokinetics of curcumin-loaded PLGA and PLGA-PEG blend nanoparticles after oral administration in rats. Colloids Surf. B Biointerfaces 2013, 101, 353-360. [CrossRef] [PubMed] 
26. Zhang, Y.; Chen, B.; Xu, S.; Li, X.; Zhang, J.; Sun, J.; Zheng, H.; Tong, L.; Sui, G.; Zhong, H.; et al. Dually functioned core-shell $\mathrm{NaYF}_{4}: \mathrm{Er}^{3+} / \mathrm{Yb}^{3+} @ \mathrm{NaYF}_{4}: \mathrm{Tm}^{3+} / \mathrm{Yb}^{3+}$ nanoparticles as nano-calorifiers and nano-thermometers for advanced photothermal therapy. Sci. Rep. 2017, 7, 11849. [CrossRef]

27. Ryabaya, O.; Prokofieva, A.; Akasov, R.; Khochenkov, D.; Emelyanova, M.; Burov, S.; Markvicheva, E.; Inshakov, A.; Stepanova, E. Metformin increases antitumor activity of MEK inhibitor binimetinib in 2D and 3D models of human metastatic melanoma cells. Biomed. Pharmacother. 2018, 109, 2548-2560. [CrossRef]

28. Mukerjee, A.; Vishwanatha, J.K. Formulation, characterization and evaluation of curcumin-loaded PLGA nanospheres for cancer therapy. Anticancer Res. 2009, 29, 3867-3875.

29. Lee, G.; Park, Y.I. Lanthanide-Doped Upconversion Nanocarriers for Drug and Gene Delivery. Nanomaterials 2018, 8, 511. [CrossRef] [PubMed]

30. Paka, G.D.; Ramassamy, C. Optimization of curcumin-loaded PEG-PLGA nanoparticles by GSH functionalization: Investigation of the internalization pathway in neuronal cells. Mol. Pharma. 2016, 14, 93-106. [CrossRef]

31. Sampath, M.; Balasubramanian, S. Rifampicin-Loaded Poly(lactic-co-glycolic) Acid Microspheres: Synthesis, Characterization, Delivery and Their Antimicrobial Studies. J. Bionanosci. 2011, 5, 47-52.

32. Singh, R.; Lillard, J.W., Jr. Nanoparticle-based targeted drug delivery. Exp. Mol. Pathol. 2009, 86, 215-223. [CrossRef]

33. Sayyar, Z.; Malmiri, H.J. Preparation, Characterization and Evaluation of Curcumin Nanodispersions Using Three Different Methods-Novel Subcritical Water Conditions, Spontaneous Emulsification and Solvent Displacement. Z. Phys. Chem. 2019, 233, 1485-1502. [CrossRef]

34. Manmode, A. Preparation and Characterization of Meselamine Loaded PLGA Nanoparticles. Int. J. Pharm. Pharm. Sci. 2011, 2, 208-214.

35. Wang, C.; Ma, C.; Wu, Z.; Liang, H.; Yan, P.; Song, J.; Ma, N.; Zhao, Q. Enhanced bioavailability and anticancer effect of curcumin-loaded electrospun nanofiber: In vitro and in vivo study. Nanoscale Res. Lett. 2015, 10, 439. [CrossRef]

36. Kamal, M.; Nazzal, S. Development of a new class of sulforaphane-enabled self-emulsifying drug delivery systems (SFN-SEDDS) by high throughput screening: A case study with curcumin. Int. J. Pharm. 2018, 539, 147-156. [CrossRef]

37. Markovic, Z.; Prekodravac, J.; Tosic, D.; Holclajtner-Antunovic, I.; Milosavljevic, M.; Dramicanin, M.; Marković, B.T. Facile synthesis of water-soluble curcumin nanocrystals. J. Serb. Chem. Soc. 2015, 80, 63-72. [CrossRef]

38. Klier, D.T.; Kumke, M.U. Analysing the effect of the crystal structure on upconversion luminescence in $\mathrm{Yb}^{3+}, \mathrm{Er}^{3+}$ co-doped $\mathrm{NaYF}_{4}$ nanomaterials. J. Mater. Chem. C 2015, 3, 11228-11238. [CrossRef]

39. Assaaoudi, H.; Shan, G.-B.; Dyck, N.C.; Demopoulos, G.P. Annealing-induced ultra-efficient NIR-to-VIS upconversion of nano-/micro-scale $\alpha$ and $\beta \mathrm{NaYF}_{4}: \mathrm{Er}^{3+}, \mathrm{Yb}^{3+}$ crystals. CrystEngComm 2013, 15, 4739-4746. [CrossRef]

40. Wilhelm, S.; Hirsch, T.; Patterson, W.M.; Scheucher, E.; Mayr, T.; Wolfbeis, O.S. Multicolor Upconversion Nanoparticles for Protein Conjugation. Theranostics 2013, 3, 239-248. [CrossRef]

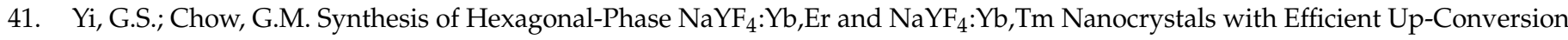
Fluorescence. Adv. Funct. Mater. 2006, 16, 2324-2329. [CrossRef]

42. Bai, X.; Xu, S.; Liu, J.; Wang, L. Upconversion luminescence tracking of gene delivery via multifunctional nanocapsules. Talanta 2016, 150, 118-124. [CrossRef] [PubMed]

43. Das, G.K.; Stark, D.T.; Kennedy, I.M. Potential Toxicity of Up-Converting Nanoparticles Encapsulated with a Bilayer Formed by Ligand Attraction. Langmuir 2014, 30, 8167-8176. [CrossRef] [PubMed]

44. Li, Z.Q.; Zhang, Y.; Jiang, S. Multicolor Core/Shell-Structured Upconversion Fluorescent Nanoparticles. Adv. Mater. 2009, 21. [CrossRef]

45. Shi, L.; Hu, J.; Wu, X.; Zhan, S.; Hu, S.; Tang, Z.; Chen, M.; Liu, Y. Upconversion core/shell nanoparticles with lowered surface quenching for fluorescence detection of $\mathrm{Hg}^{2+}$ ions. Dalton Trans. 2018, 47, 16445-16452. [CrossRef] [PubMed]

46. Dias, L.D.; Blanco, K.C.; Mfouo-Tynga, I.S.; Inada, N.M.; Bagnato, V.S. Curcumin as a photosensitizer: From molecular structure to recent advances in antimicrobial photodynamic therapy. J. Photochem. Photobiol. C Photochem. Rev. 2020, 45, 100384. [CrossRef]

47. Kazantzis, C.; Koutsonikoli, K.; Mavroidi, B.; Zachariadis, M.; Alexiou, P.; Pelecanou, M.; Politopoulos, K.; Alexandratou, E.; Sagnou, M. Curcumin derivatives as photosensitizers in photodynamic therapy: Photophysical properties and in vitro studies with prostate cancer cells. Photochem. Photobiol. Sci. 2020, 19, 193-206. [CrossRef]

48. Dev, A.; Srivastava, A.K.; Choudhury, S.R.; Karmakar, S. Nano-curcumin influences blue light photodynamic therapy for restraining glioblastoma stem cells growth. RSC Adv. 2016, 6, 95165-95168. [CrossRef]

49. Leite, D.P.V.; Paolillo, F.R.; Parmesano, T.N.; Fontana, C.R.; Bagnato, V.S. Effects of Photodynamic Therapy with Blue Light and Curcumin as Mouth Rinse for Oral Disinfection: A Randomized Controlled Trial. Photomed. Laser Surg. 2014, 32, 627-632. [CrossRef]

50. Simões, J.C.S.; Sarpaki, S.; Papadimitroulas, P.; Therrien, B.; Loudos, G. Conjugated Photosensitizers for Imaging and PDT in Cancer Research. J. Med. Chem. 2020, 63, 14119-14150. [CrossRef]

51. Das, A.; Bagot, C.C.; Rappeport, E.; Tis, T.B.; Park, W. Quantitative modeling and experimental verification of Förster resonant energy transfer in upconversion nanoparticle biosensors. J. Appl. Phys. 2021, 130, 023102. [CrossRef]

52. Ye, Y.; Li, Y.; Fang, F. Upconversion nanoparticles conjugated with curcumin as a photosensitizer to inhibit methicillin-resistant Staphylococcus aureus in lung under near infrared light. Int. J. Nanomed. 2014, 9, 5157-5165. [CrossRef] 
53. Shahcheraghi, S.H.; Zangui, M.; Lotfi, M.; Ghayour-Mobarhan, M.; Ghorbani, A.; Jaliani, H.Z.; Sadeghnia, H.R.; Sahebkar, A. Therapeutic Potential of Curcumin in the Treatment of Glioblastoma Multiforme. Curr. Pharm. Des. 2019, 25, 333-342. [CrossRef]

54. Wang, X.; Deng, J.; Yuan, J.; Tang, X.; Wang, Y.; Chen, H.; Liu, Y.; Zhou, L. Curcumin exerts its tumor suppressive function via inhibition of NEDD4 oncoprotein in glioma cancer cells. Int. J. Oncol. 2017, 51, 467-477. [CrossRef]

55. Lin, Q.; Li, W.; Liu, D.; Zhao, M.; Zhu, X.; Li, W.; Wang, L.; Zheng, T.; Li, J. Porous Silicon Carrier Delivery System for Curcumin: Preparation, Characterization, and Cytotoxicity in Vitro. ACS Appl. Bio Mater. 2019, 2, 1041-1049. [CrossRef]

56. Mironova, K.E.; Khochenkov, D.A.; Generalova, A.N.; Rocheva, V.V.; Sholina, N.V.; Nechaev, A.V.; Semchishen, V.A.; Deyev, S.M.; Zvyagin, A.V.; Khaydukov, E.V. Ultraviolet phototoxicity of upconversion nanoparticles illuminated with near-infrared light. Nanoscale 2017, 9, 14921. [CrossRef]

57. Khaydukov, E.; Mironova, K.; Semchishen, V.A.; Generalova, A.; Nechaev, A.; Khochenkov, D.A.; Stepanova, E.V.; Lebedev, O.I.; Zvyagin, A.V.; Deyev, S.M.; et al. Riboflavin photoactivation by upconversion nanoparticles for cancer treatment. Sci. Rep. 2016, 6, 35103. [CrossRef]

58. Nunes, A.S.; Barros, A.S.; Costa, E.C.; Moreira, A.F.; Correia, I.J. 3D tumor spheroids as in vitro models to mimic in vivo human solid tumors resistance to therapeutic drugs. Biotechnol. Bioeng. 2018, 116, 206-226. [CrossRef]

59. Costa, E.C.; Moreira, A.F.; Diogo, D.M.D.M.; Gaspar, V.; Carvalho, M.P.; Correia, I.J. 3D tumor spheroids: An overview on the tools and techniques used for their analysis. Biotechnol. Adv. 2016, 34, 1427-1441. [CrossRef] [PubMed] 